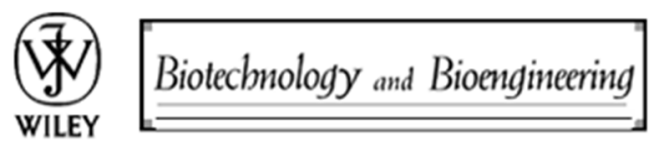

\title{
On-chip assessment of human primary cardiac fibroblasts proliferative responses to uniaxial cyclic mechanical strain
}

\begin{tabular}{|r|l|}
\hline Journal: & Biotechnology and Bioengineering \\
\hline Manuscript ID: & $15-581$. R1 \\
\hline Wiley - Manuscript type: & Article \\
\hline Complete List of Authors: & $\begin{array}{l}\text { Ugolini, Giovanni Stefano; Politecnico di Milano, Department of Electronics, } \\
\text { Information and Bioengineering } \\
\text { Rasponi, Marco; Politecnico di Milano, Bioengineering department } \\
\text { Pavesi, Andrea; Politecnico di Milano, Dipartimento di Elettronica, } \\
\text { Informazione e Bioingegneria } \\
\text { Santoro, Rosaria; Centro Cardiologico Monzino, Unità di Ingegneria } \\
\text { Tissutale } \\
\text { Kamm, Roger; MIT, Mechanical Engineering } \\
\text { Fiore, Gianfranco; Politecnico di Milano, Bioengineering department } \\
\text { Pesce, Maurizio; Centro Cardiologico Monzino, Unità di Ingegneria Tissutale } \\
\text { Soncini, Monica; Politecnico di Milano, Dipartimento di Bioingeneria }\end{array}$ \\
\hline Key Words: & $\begin{array}{l}\text { microdevice, cyclic strain, human cardiac fibroblast, mechanobiology, cell } \\
\text { proliferation, mechanotransduction }\end{array}$ \\
\hline
\end{tabular}


1 On-chip assessment of human primary cardiac fibroblasts proliferative responses to

2 uniaxial cyclic mechanical strain

3 Giovanni Stefano Ugolini ${ }^{1 \dagger}$, Marco Rasponi ${ }^{1}$, Andrea Pavesi ${ }^{2}$, Rosaria Santoro ${ }^{3}$, Roger

$4 \mathrm{Kamm}^{4}$, Gianfranco Beniamino Fiore ${ }^{1}$, Maurizio Pesce ${ }^{3}$ and Monica Soncini ${ }^{1}$

5 Affiliations:

$6{ }^{1}$ Department of Electronics, Information and Bioengineering. Politecnico di Milano. Milan

7 (ITALY)

$8{ }^{2}$ Biosym IRG, Singapore-MIT Alliance for Research and Technology. Singapore

9 (SINGAPORE)

$10{ }^{3}$ Unità di Ingegneria Tissutale Cardiovascolare. Centro Cardiologico Monzino IRCCS. Milan 11 (ITALY)

$12{ }^{4}$ Department of Biological Engineering. Massachusetts Institute of Technology. Cambridge 13 (USA)

$14{ }^{\dagger}$ Corresponding author. Politecnico di Milano. Department of Electronics, Information and 15 Bioengineering Via Golgi 39 - 20133 Milano. E-mail: giovannistefano.ugolini@polimi.it Tel 16 (office): +39 0223994144 Fax: +39 0223993360 


\section{Abstract:}

2 Cardiac cell function is substantially influenced by the nature and intensity of the mechanical 3 loads the cells experience. Cardiac fibroblasts (CFs) are primarily involved in myocardial 4 tissue remodeling: at the onset of specific pathological conditions, CFs activate, proliferate, 5 differentiate and critically alter the amount of myocardial extra-cellular matrix with important 6 consequences for myocardial functioning. While cyclic mechanical strain has been shown to 7 increase matrix synthesis of CFs in vitro, the role of mechanical cues in CFs proliferation is 8 unclear. We here developed a multi-chamber cell straining microdevice for cell cultures 9 under uniform, uniaxial cyclic strain. After careful characterization of the strain field, we 10 extracted human heart-derived CFs and performed cyclic strain experiments. We subjected 11 cells to $2 \%$ or $8 \%$ cyclic strain for $24 \mathrm{~h}$ or $72 \mathrm{~h}$, using immunofluorescence to investigate 12 markers of cell morphology, cell proliferation (Ki67, EdU, phospho-Histone-H3) and 13 subcellular localization of the mechanotransduction-associated transcription factor YAP. Cell 14 morphology was affected by cyclic strain in terms of cell area, cell and nuclear shape and 15 cellular alignment. We additionally observed a strain intensity-dependent control of cell 16 growth: a significant proliferation increase occurred at $2 \%$ cyclic strain, while time17 dependent effects took place upon 8\% cyclic strain. The YAP-dependent mechano18 transduction pathway was similarly activated in both strain conditions. These results 19 demonstrate a differential effect of cyclic strain intensity on human CFs proliferation control 20 and provide insights into the YAP-dependent mechano-sensing machinery of human CFs.

21

22 Keywords: Microdevice, cyclic strain, human cardiac fibroblasts, mechanobiology, cell 23 proliferation, mechanotransduction

25 Submitted to: Biotechnology and Bioengineering 
1 I. INTRODUCTION Owing to cardiac contractility, the myocardium represents a highly dynamic

3 mechanical microenvironment for cardiac cells. Specific cardiac cell functions are either

4 activated or repressed, depending on the magnitude of mechanical load sensed by the 5 intracellular signal transduction machinery, with consequences for physiological or 6 pathological tissue evolution (Curtis and Russell, 2011; Ruwhof and Van Der Laarse, 2000;

7 Sadoshima and Izumo, 1997; Shyu, 2009; Yamazaki et al., 1995).

8 The most abundant cell type by number in the human heart is the cardiac fibroblast, 9 accounting for more than half of the total number of cardiac cells and responsible for a 10 variety of functions: synthesizing cardiac ECM components, participating in cardiac pacing 11 and secreting cytokines necessary for cardiac homeostasis (Eghbali, 1992; Souders et al., 12 2009; Zeisberg and Kalluri, 2010). Cardiac fibroblasts (CFs) are the main actors in cardiac 13 tissue remodeling: upon pathological tissue conditions such as ischemia (Cosentino et al., 14 2014; Porter and Turner, 2009) or mechanical overload (Berk et al., 2007), CFs altered 15 behavior leads to unbalanced synthesis and degradation of ECM resulting in myocardial 16 stiffening, fibrosis and reduced contractility (Fan et al., 2012; Krenning et al., 2010). The 17 hallmark of this pathological CFs behavior is the differentiation of resident CFs into 18 myofibroblasts, a contractile and matrix-producing cell type that expresses smooth muscle 19 cells markers. In vitro studies have clearly linked this phenotypic switch (Schroer and 20 Merryman, 2015; Tomasek et al., 2002) and CFs increased ECM deposition (Watson et al., 21 2012; Watson et al., 2014; Butt and Bishop, 1997; Carver et al., 1991; Gupta and Grande22 Allen, 2006; Husse et al., 2007; Lee et al., 1999; Lindahl et al., 2002; Mackenna et al., 2000; 23 Ruwhof et al., 2000) to mechanical cues, suggesting the mechanical microenvironment as a 24 factor in the onset or progression of fibrotic cardiac disease. However, CFs proliferation 25 dynamics seem also to play a role in the evolution of cardiac fibrosis, as demonstrated by in 26 vivo studies that report an increased number of resident CFs in pathological myocardial 
1 conditions (Lucas et al., 2010; Moore-Morris et al., 2014). This proliferative response is not

2 well characterized by in vitro studies at the cellular level nor it has been clearly correlated to

3 mechanical stimuli: a limited number of studies on rat CFs reported both decreased (Atance

4 et al., 2004; Butt and Bishop, 1997; Liao et al., 2004) and increased (Dalla Costa et al., 2010)

5 proliferation under mechanical load.

6 The nature of the mechanical stimulus experienced by cardiac cells in vivo is extremely

7 complex: the strain field is three-dimensional, multi-directional and highly variable

8 throughout the organ (Garot et al., 2000; Gorcsan and Tanaka, 2011). In vitro, this

9 complexity is often modeled and simplified by systems that allow for cell cultures on

10 cyclically strained 2D substrates. In order to precisely identify characteristic behaviors of

11 cardiac cells subject to cyclic strain, the ability to apply finely controllable, highly uniform

12 strain fields in vitro is of paramount importance. Custom-made or commercially available

13 systems for cell culture under cyclic strain are based on pneumatic (Kreutzer et al., 2014;

14 Wang et al., 2010) or motorized (Gerstmair et al., 2009; Huang et al., 2010; Yost et al., 2000)

15 actuation. With particular respect to the pneumatic commercial platform FlexCell (FlexCell

16 International Corp., Hillsborough, NC) it has been demonstrated that it suffers from

17 limitations in terms of strain field non-uniformities, calibration issues, operational

18 complexities and low-throughput (Colombo et al., 2008; Vande Geest et al., 2004). In motor-

19 driven uniaxial stretching platforms, where the stretched culture membrane sides are free to

20 deform, the resulting strain field typically has a longitudinal component along the direction of

21 motion of the motor but also a transverse, non-negligible, component (Shao et al., 2013). In

22 summary, available culture platforms often apply different strain fields to 2D cell cultures in

23 terms of directionality (biaxial, uniaxial, equi-biaxial) and the level of control on the strain

24 field uniformity is often insufficient to conduct systematic and comparable biological studies. 
1 A sound experimental criterion to systematically explore cell behaviors under mechanical

2 strain is therefore to improve the control and uniformity of the stimulus applied.

3 In this work, we investigated the response of human adult heart-derived CFs to

4 different cyclic uniaxial strain intensities by employing a custom designed microdevice.

5 Typical advantages of microfluidic devices include the requirement of small amounts of cells

6 and reagents. However, the small amounts of biological materials cultured are often not

7 compatible with some biological assays such as gene (qPCR) or protein (Western Blot)

8 expression analyses. Micro-scale stretching systems include pressure or piezo-electrically

9 strained thin membranes (Shimizu et al., 2011; Simmons et al., 2011; Wang et al., 2013) and

10 systems where a thin membrane is deformed by application of vacuum into side chambers

11 (Ao et al., 2015; Huang et al., 2013; Huh et al., 2010; Pavesi et al., 2015; Tremblay et al., 12 2014). Building on a previous concept (Huh et al., 2010), we developed a multi-chamber cell 13 straining microdevice that allows for cell culture under finely controlled uniaxial and uniform 14 mechanical strain. We adopted engineering tools during device development to design and 15 characterize the strain field and we included the possibility of conducting four parallel and 16 independent cell cultures in the same microdevice to increase throughput. The ability to apply 17 finely controlled strain fields in a high-throughput fashion and the small amounts of cells 18 required enabled us to perform controlled cyclic strain experiments on freshly isolated human 19 primary CFs subject to different strain intensities. We subjected cells to strain intensities 20 representative of physiological myocardial contraction ( $8 \%$ strain) and reduced myocardial 21 contraction ( $2 \%$ strain) and we investigated human CFs responses in terms of cell 22 morphology, proliferation rate and mechano-transduction. We identified a time- and a strain23 dependent relationship between cell straining and control of CF mitosis and proliferation. We 24 investigated the possible involvement of a mechano-sensing-associated transcription factor 25 (YAP) in the control and modulation of the proliferative responses we observed. The YAP 
1 transcription factor is one of the master components of the Hippo pathway, involved in heart

2 development and growth (Heallen et al., 2011; Papizan and Olson, 2014), in reactivation of

3 cardiac myocytes proliferation (Xin et al., 2013), in myocardial damage sensing by cardiac

4 progenitors (Mosqueira et al., 2014), and recently implicated in mechano-sensing and

5 geometry-associated mitotic checkpoints (Aragona et al., 2013; Dupont et al., 2011).

6 II. MATERIALS AND METHODS

7 A. Stretching unit design

8 The microdevice is fabricated in polydimethylsiloxane (PDMS, Sylgard 184, Dow

9 Corning) and consists of four separate stretching units each featuring a thin deformable

10 PDMS membrane sandwiched between two PDMS layers (Figure 1A). Each of the top and

11 bottom layers contains two flanking actuation chambers (Fig. 1A, red) that, upon application

12 of controlled negative pressure, uniformly stretch the central thin membrane. The chamber

13 located above the thin membrane contains the cell culture (Fig 1A, blue) whereas the fluid

14 chamber below the membrane allows for environmental conditioning of the upper culture

15 chamber through gas or small-molecules exchange (Fig. 1A, green). The design of the

16 stretching unit geometry was dictated by the following requirements: generating up to $8 \%$

17 membrane strain and allowing a cell culture region of $5 \mathrm{~mm}^{2}$ (sufficient to seed more than

181000 cells, depending on cell type and density). The final cross-sectional geometry is shown

19 in Figure 1A whereas all geometric parameters and the details of the stretching unit design 20 are reported in Supplementary Material S1.

21 B. Multi-chamber microdevice design

22 Four stretching units were incorporated into a single device, each actuated by a 23 common pneumatic circuit and featuring a single, common lower fluidic circuit. The culture 24 chambers, however, are completely independent and each is accessible from two wells. As 25 shown in Figure 1B, the device is comprised of a top layer that includes culture chambers 26 (blue), upper halves of the side actuation chambers (red), and pneumatic actuation circuit 
1 (red) and a bottom layer that includes a lower fluidic circuit connecting the fluidic chambers

2 (green) and the lower halves of the side actuation chambers (red). These layouts were drawn

3 through CAD software (AutoCAD, AutoDeskInc). Transparency masks were printed at high-

4 resolution (32,000 dpi) and used as photomasks in the subsequent photolithography steps.

5 C. Microdevice fabrication

6 Devices were realized through PDMS replica molding using microstructured silicon

7 wafers as molds. Wafer preparation utilized deep reactive-ion etching (DRIE) technique;

8 details of the procedure are described in Supplementary Material S2. All components of the

9 microdevice were fabricated in PDMS, used at a 10:1 (w/w) pre-polymer to curing agent ratio.

10 Both layers were obtained by casting PDMS directly on the corresponding molds. The thin

11 membrane was fabricated by spin-coating liquid PDMS at 900rpm for 30s on a clean silicon

12 wafer, resulting in a thickness of $80 \mu \mathrm{m}$. Before assembling membrane and upper layer,

13 through-holes were punched in the upper layer to create wells for the culture chambers $(5 \mathrm{~mm}$

14 and $6 \mathrm{~mm}$ diameters), and inlets for the pneumatic actuation circuit (1mm diameter) and for

15 the lower fluidic circuit ( $1 \mathrm{~mm}$ diameter). Upper layer and membrane were plasma bonded

16 (Plasma Cleaner, Harrick Plasma, 60s, 10W) and then cut and lifted off the silicon wafer. At

17 this stage, small holes were made on the thin membrane matching the side actuation

18 chambers by using sharp fine-tip tweezers. This step resulted critical for successfully

19 delivering negative pressure actuation to both upper halves and lower halves of the side

20 actuation chambers. Finally, the upper layer and membrane complex was bonded to the lower

21 layer after plasma activation and careful alignment under a stereomicroscope. The

22 microdevices were finally sterilized by autoclaving $\left(121^{\circ} \mathrm{C}, 20 \mathrm{~min}\right.$, wet cycle), dried at $80^{\circ} \mathrm{C}$

23 overnight and stored until use. An image of a fabricated microdevice is shown in Figure 1C.

24 D. Microdevice characterization

25 The membrane strain field was characterized by mixing graphite powder (diameter 
1 smaller than $20 \mu \mathrm{m}$, Sigma, Italy) with liquid PDMS $(1: 1000, \mathrm{w} / \mathrm{w})$ before membrane

2 fabrication. The graphite particles allowed the strain field to be quantified at different

3 negative pressures applied in the side chambers. In total, a number of 10 culture chambers

4 from a pool of 5 devices were analyzed: for each chamber, 7 images were taken (1X

5 magnification, stereomicroscope) at pressure values ranging from $0 \mathrm{mmHg}$ to $-600 \mathrm{mmHg}$

6 with a step of $100 \mathrm{mmHg}$. ImageJ software (v. 1.47f-software for Java, National Institutes of

7 Health, USA) was employed to measure displacements (minimum 5 measures per image) and

8 estimate average strain. These data were used to draw strain-pressure relations. In addition, a

9 Digital Image Correlation algorithm (Improved Digital Image Correlation, MATLAB) was

10 employed to estimate full-field displacements and strains on the membranes. This calculation

11 was carried out for 3 microdevices at an applied pressure of $-500 \mathrm{mmHg}$ and yielded 2D strain

12 field maps for each considered culture membrane. In order to evaluate strain field uniformity

13 and uniaxiality, $\varepsilon_{\mathrm{yy}}$ and $\varepsilon_{\mathrm{xx}}$ strain components were computed, where $\mathrm{x}$ is the channel main

14 axis. Local strain values were extracted from 2D strain field maps to quantify regional strain

15 variations throughout the entire culture membrane and to define the region where the strain

16 field is highly uniform and uniaxial. To this purpose, nine regions were analyzed along the

17 length (main axis) of the culture channel and from each region three sub-regions were

18 considered along the width of the channel: central membrane region and top and bottom

19 regions, closer to the channel walls.

20 E. Cell isolation and culture

21 Samples from patient atria were obtained under informed consent. Details of human

22 CFs isolation (Agocha and Eghbali-Webb, 1997; Gambini et al., 2011; Neuss et al., 1996;

23 Rossini et al., 2008) and medium composition are described in Supplementary Material S3.

24 Before cell seeding, devices were plasma treated and coated with human fibronectin

$25(25 \mu \mathrm{g} / \mathrm{ml}, 30 \mathrm{~min}$ incubation; Sigma Aldrich, USA). Cells were seeded at a passage number 
1 of 3 by manually injecting $100 \mu \mathrm{l}$ of cell solution into each culture chamber and allowing 2 adhesion to the membrane for $16 \mathrm{~h}$ into an environmental incubator $\left(37^{\circ} \mathrm{C}, 5 \% \mathrm{CO}_{2}\right)$. The cell 3 concentration value was set to $10^{6}$ cells $/ \mathrm{ml}$ following preliminary cell adhesion experiments.

4 Subsequently, controlled cyclic strain $(2 \%$ or $8 \%$ ) was applied to the culture chambers at $1 \mathrm{~Hz}$ 5 for $24 \mathrm{~h}$ or $72 \mathrm{~h}$. Negative pressure was delivered through a standard laboratory vacuum line, 6 controlled by a high-precision pressure regulator and actuated through an electronically 7 controlled electro-pneumatic valve. Culture medium was changed every $12 \mathrm{~h}$. No 8 environmental conditioning was applied in this study and lower fluidic channels were 9 therefore left open to the incubator atmosphere. For each condition tested, static microdevices 10 (without application of cyclic strain) were also cultured as control. For proliferation and 11 mechano-transduction studies, the minimum number of biological replicates was 4 , whereas 12 for morphological studies we performed analyses for a minimum of 6 biological replicates.

\section{F. Immunofluorescence}

14 Cells were fixed with 4\% paraformaldehyde in PBS for 10 minutes. After blocking and 15 permeabilizing for $1 \mathrm{~h}$ at room temperature with PBS containing $3 \%$ bovine serum albumin 16 and $0.1 \%$ Triton-X, cells were incubated for $2 \mathrm{~h}$ at room temperature with the following 17 primary antibodies: anti-Ki67 (rabbit, AbCam, UK), for proliferating cells (cell cycle phases: 18 G1 through M); anti-phospho-Histone-H3 (Ser10, rabbit, Santa-Cruz, US), for mitotic cells; 19 anti-YAP (rabbit, Santa-Cruz, US), to identify nuclear or cytoplasmic localization of the $20 \mathrm{YAP} / \mathrm{TAZ}$ protein complex. Cells were then probed for $1 \mathrm{~h}$ at room temperature with Alexa 21 Fluor 488-conjugated secondary antibodies (Invitrogen). Nuclear staining was performed by 22 incubating cells with DAPI whereas actin staining was performed with rhodamine-conjugated 23 Phalloidin. Negative controls were present for all immunofluorescence stainings.

\section{G. EdU incorporation assays}


1 Cells undergoing active DNA synthesis during S-phase were evaluated with Click-It

2 EdU Alexa Fluor 488 Imaging Kit (Invitrogen). The cell culture medium was switched to 3 medium including $10 \mu \mathrm{M}$ EdU. After $2 \mathrm{~h}$ incubation at $37^{\circ} \mathrm{C}$, cells were fixed with $4 \%$

4 paraformaldehyde and probed with the Alexa Fluor 488 azide in the standard concentration

5 and buffer provided by the kit.

\section{$6 \quad$ H. Image acquisition and processing}

7 Images were acquired with a Zeiss Apotome/LSM 710 confocal microscope. Three 8 images per culture chamber were taken at 10X magnification, thus sampling roughly half of

9 the total area of the culture region. Acquisition parameters were not changed throughout the 10 imaging of each experiment. ImageJ software (v. 1.47f-software for Java, National Institutes 11 of Health, USA) was employed for all image processing. Cell morphology was evaluated by 12 calculating nuclear shape index, cell shape index and cell spread area. The shape index is 13 calculated as $4 \pi \cdot$ area/(perimeter) ${ }^{2}$ and ranges between one (circular shape) and zero (linear 14 shape). This relationship was used to calculate both nuclear shape index and cell shape index. 15 Nuclear shape index was automatically calculated by fitting ellipses to projected nuclei in 16 binarized DAPI images and using perimeter and area values of the fit ellipses. About 500 17 cells per replicate were sampled for this analysis. Cell shape index was manually calculated 18 by drawing cell outlines in Phalloidin images for a minimum of 20 cells per replicate. This 19 operation also yielded cell area values. Only cells with clear, non-overlapping outlines were 20 considered for this analysis. One blinded individual performed cell outlines drawing. Cell 21 orientation was calculated as the angle formed by the main axis of the ellipse that fits a 22 nucleus and the direction perpendicular to the strain, i.e. the channel main axis. For this 23 specific parameter, statistical analyses were performed by comparing the fraction of aligned 24 cells, where an aligned cell is a cell with a nuclear angle of $0^{\circ} \pm 10^{\circ}$ with the channel main 25 axis. 
1 Cell proliferation analyses were performed by manually counting nuclei positive for a 2 given marker and dividing by the total number of nuclei (automatically counted) to estimate 3 the level of expression. About 500 cells per replicate were screened for proliferation analyses.

4 YAP translocation analyses were performed by manually counting YAP-positive nuclei. In 5 addition, calculations of nuclear fluorescence intensity were also performed in order to 6 corroborate the manual counts. Nuclear fluorescence intensity was calculated by using the 7 DAPI channel of images as a mask in the YAP channels to limit the calculation to nuclei only.

8 Subsequently, the integrated signal density was extracted, corrected for background, 9 normalized for nucleus area and used as final intensity value. For YAP localization analyses, 10 about 500 cells per replicate were sampled with manual counts and at least 45 nuclei per 11 replicate were analyzed with fluorescence intensity calculations.

\section{I. Statistical analysis}

13 All data are presented as mean \pm SD. Statistical comparisons were performed using 14 GraphPad 5 (Prism) software. All data were initially analyzed for normality using 15 Kolmogorov-Smirnov tests and then compared using parametric t-tests, one-way ANOVA or 16 non-parametric Mann-Whitney or Kruskal-Wallis tests, where appropriate. A $p$ value less 17 than 0.05 was assumed as statistically significant.

\section{III. RESULTS}

\section{A. Microdevice characterization}

20 Tracking displacements and calculating membrane full-field strains allowed for an in21 depth characterization of the strain field experienced by cells in the culture chamber. A linear 22 correlation was observed between average strain intensity and increasing negative pressures 23 (Fig. 2A). Strain intensity reached about $8 \%$ at $-600 \mathrm{mmHg}$, which is in good agreement with 24 the strain values predicted by numerical simulations (Supplementary Material S1). Figure 2B 25 shows 2D strain field maps for a representative microdevice; strain maps for a set of 3 26 microdevices can be found in Supplementary Material S4. The quantification of regional 
1 strain variations demonstrated the strain field uniformity (Fig. 2B): with an average applied

2 strain of $5.7 \%$, the average standard deviation of $\varepsilon_{y y}$ values along both width and length of

3 the channel resulted to be $0.3 \%$. The strain field also resulted highly uniaxial with an average

$4 \varepsilon_{\mathrm{xx}}$ value as low as $0.4 \%$. No significant variation was observed in $\varepsilon_{\mathrm{xx}}$ values throughout most

5 of the culture membrane (Fig. 2B). Only the lateral regions close to the chamber ends

6 exhibited significantly different $\varepsilon_{\mathrm{xx}}$ values compared to all other regions (One-way ANOVA

7 followed by Bonferroni post-hoc test, $\mathrm{p}<0.05$ ). For this reason, we defined a controlled strain

8 field area of the culture membrane that extends for $4.5 \mathrm{~mm}$ along channel length, where the

9 total culture channel length is $5 \mathrm{~mm}$. This area is shown in Figure $2 \mathrm{C}$ and is the effective

10 observation area sampled during subsequent cell culture experiments.

11 B. Cell morphology and cell orientation

12 Figure 3 shows representative images of CFs cultured under control, 2\% cyclic strain 13 and $8 \%$ cyclic strain conditions at $24 \mathrm{~h}$ (Fig. 3A) and $72 \mathrm{~h}$ (Fig. 3B) and their orientation, 14 expressed as relative frequency distributions of angles between nuclear main axis and the 15 longitudinal axis. Cell area (Fig. 3C) increased two-fold between $24 \mathrm{~h}$ and $72 \mathrm{~h}$ culture time 16 only in control condition, whereas no significant change in cell area took place when cells 17 were subjected to either $2 \%$ or $8 \%$ cyclic strain. Cell shape index decreased with the 18 application of strain (Fig. 3D): cells cultured under $2 \%$ cyclic strain showed a slight 19 significant decrease of their shape index after $24 \mathrm{~h}$ and $72 \mathrm{~h}$, whereas a two-fold decrease is 20 reported for cells subjected to $8 \%$ cyclic strain at both $24 \mathrm{~h}$ and $72 \mathrm{~h}$. We analyzed the 21 correlation between cell area and cell shape index and found no significant correlation 22 (Supplementary Material S5). No significant change occurred in nuclear shape index (Fig. 23 3E) except for cells cultured for $72 \mathrm{~h}$ under $8 \%$ cyclic strain that exhibited a slight significant 24 reduction of the nuclear shape index. These results indicate cyclic strain as a general 
1 regulator of CFs elongation and size growth arrest. In addition, large strains (8\%) trigger

2 nuclear elongation, a phenomenon not induced by smaller strain fields $(2 \%)$.

3 Cell orientation analyses were also performed after $24 \mathrm{~h}$ and $72 \mathrm{~h}$ at both $2 \%$ and $8 \%$

4 cyclic strain. The major effect we observed is a collective alignment of the cells main axis

5 orthogonally to the strain field. This is a known cell behavior under cyclic strain (Terracio et

6 al., 1988). Statistical analyses of the number of aligned cells per condition (Fig. 3F) show that

7 a significant increase of aligned cells only occurs with $8 \%$ cyclic strain and is more

8 pronounced after $72 \mathrm{~h}$ of stimulus. Cells cultured under $2 \%$ cyclic strain showed no

9 significant difference from control cells in terms of orientation. Accordingly, representative

10 frequency distributions (Fig. 3A,B) of nuclear angles show a uniformly scattered distribution

11 of angles in cells cultured in control condition or under $2 \%$ cyclic strain whereas a 12 preferential orientation towards the longitudinal direction is reported for cells subject to $8 \%$ 13 cyclic strain.

14 C. Cell-cycle markers expression

15 To assess the effects of mechanical strain on CFs ability to proliferate, we performed 16 immunofluorescence analyses to detect cellular antigens expressed in actively proliferating 17 cells (Ki67), in mitotic cells (phospho-Histone-H3; PHH3) and by assessing the ability to 18 synthesize DNA (labeling with EdU) indicative of cells in S phase. Figure 4 shows the 19 fraction of cells positive to the above markers with respect to time ( $24 \mathrm{~h}$ and $72 \mathrm{~h}$ ) and strain 20 intensity ( $2 \%$ and $8 \%)$ along with representative images.

21 No significant changes were found in the levels of Ki67 expressing cells (Fig. 4A,B). 22 Figures $4 \mathrm{C}$ and $4 \mathrm{D}$ show the fraction of cells that incorporated EdU: after $72 \mathrm{~h}$ of stimulus, a 23 two-fold significant increase in EdU incorporation was found in cells subject to $2 \%$ cyclic 24 strain, whereas no variation occurred in cells subject to $8 \%$ cyclic strain. Additional analyses 25 took into account the influence of cell density on EdU incorporation: Figure 5 shows the EdU 
1 incorporation values plotted against the cell density in which they were observed. Values

2 obtained under $2 \%$ strain are significantly higher than values obtained under control or $8 \%$

3 strain conditions.

4 Interestingly, cyclic strain induced an up-regulation of PHH3 labeling as well (Fig.

5 4E,F,G). Cells cultured under $2 \%$ cyclic strain showed a four-fold increase in the expression 6 of $\mathrm{PHH} 3$, a result that is stable in time from $24 \mathrm{~h}$ to $72 \mathrm{~h}$. Cells cultured under $8 \%$ cyclic strain 7 showed a similar increase in mitotic cells only at $24 \mathrm{~h}$, with values of $\mathrm{PHH} 3$ expression 8 decreasing to the same level as controls after $72 \mathrm{~h}$ of stimulus. Finally, by performing

9 standard nuclei counts to evaluate the number of cells in each culture condition, we observed 10 that cells subjected to $2 \%$ cyclic strain significantly increased in number compared to both 11 control and 8\% strain conditions (Fig. 4H).

\section{D. YAP localization}

13 The nuclear translocation of YAP has been directly involved in the control of mitotic 14 checkpoints associated to differential cytoskeletal tension (Aragona et al., 2013; Dupont et al., 15 2011) as well as in a cyclic strain-induced proliferation of epithelial cell lines (Codelia et al., 16 2013). Since the cytoskeleton was differentially affected by $2 \%$ and $8 \%$ strain conditions, and 17 in light of the proliferative responses of CFs under different strain conditions, we investigated 18 whether the effect of on-chip cyclic strain stimulation was associated with modifications in 19 the subcellular distribution of the YAP protein. We manually quantified the localization of 20 YAP as nuclear or cytoplasmic by visual discrimination. Given the subjective nature of this 21 count, this data were corroborated with calculations of nuclear fluorescence intensity. Both 22 strain conditions caused a significant nuclear translocation of the YAP protein after $72 \mathrm{~h}$ of 23 strain (Fig. 6). In addition, we explored possible correlations between YAP nuclear intensity 24 and cell morphology parameters and found an increasing nuclear YAP expression with 25 increasing cell area values only under 2\% strain (Supplementary Material S5). 


\section{DISCUSSION}

Activation, proliferation and differentiation of CFs into pro-inflammatory and matrix

3 stiffening cells is a critical step in the development of pressure overload- or ischemia-related

4 myocardial fibrosis. Relating these cellular behaviors to mechanical cues requires in vitro

5 platforms capable of applying highly uniform and controlled mechanical stimuli.

6 In this work we inspired to a previous concept (Huh et al., 2010) and designed,

7 fabricated and characterized a microdevice for cyclic uniaxial strain of cell monolayers with

8 rigorous quantification of the real mechanical stimulus applied. The microdevice produced

9 extremely uniform and uniaxial strain (no significant excursions of $\varepsilon_{y y}$ values throughout the

10 membrane and $\varepsilon_{\mathrm{xx}}$ strain values closely approaching zero), a feature present with a

11 significantly lower level of control in other large-scale stretching devices. In addition, we

12 included four test sites per device, in order to enable quick screenings and higher throughputs.

13 Although not exploited in the present study, the microfluidic platform was also provided with

14 an embedded lower fluidic system for the environmental conditioning of cultured cells in all

15 four culture chambers. The main limitations of the platform, related to the small volume of

16 the culture chambers, are the small number of cells to perform gene and protein expression

17 analyses and the frequent medium changing requirements.

18 We employed this microdevice to screen human heart-derived adult CFs responses to

19 different cyclic strain intensities. Due to the small dimensions of typical heart biopsies, the

20 supply of human heart-derived CFs is limited. Previous cyclic strain studies of human CFs

21 were indeed performed on purchased cells, rather than on CFs freshly isolated from tissue

22 samples (Watson et al., 2012). By employing our custom-designed microdevice, we managed

23 to perform experiments on cells freshly isolated directly from atrial tissue. Typical

24 amplification steps were required, that may cause alterations in cellular behavior. However,

25 the small number of cells needed to load each culture chamber of the microdevice enabled us

26 to conduct experiments after only two amplification passages before functional analyses, thus 
1 maximizing the reliability and the relevance of the results. We subjected cells to controlled

$22 \%$ and $8 \%$ cyclic strain: although these strain intensities are simplified mechanical

3 conditions, we based on cardiac imaging studies (Almaas et al., 2014; Donekal et al., 2014)

4 and we related the $8 \%$ strain condition to the average strain field sensed in the physiological

5 cardiac cycle, whereas we suggest that $2 \%$ strain may represent a fibrotic mechanical

6 environment, where the myocardial ability to contract is reduced.

7 We first explored the effects of differential cyclic strain intensities and straining time

8 on CFs morphology. We observed strain-specific effects on cellular alignment along the

9 orthogonal direction to the strain field, that occurred consistently only with a higher $8 \%$ strain

10 level and especially after $72 \mathrm{~h}$ of stimulation. This is consistent with literature on stretched

11 fibroblasts, although shorter time-scales have been reported for skin fibroblasts (Neidlinger-

12 Wilke et al., 2002). By contrast, no major rearrangement was observed in cells undergoing

13 lower $2 \%$ cyclic strain. The modifications in cell elongation show that, although not altering

14 the cellular orientation, $2 \%$ cyclic strain was able to consistently engage the CFs cytoskeleton

15 by increasing cell elongation. However, this elongation effect is significantly more

16 pronounced and affects the nuclear shape only when cells are subject to $8 \%$ cyclic strain. We

17 also report that cyclic strain hinders cell size growth similarly for $2 \%$ and $8 \%$ strains.

18 We then explored the proliferative response of CFs, focusing on different cell 19 proliferation markers: the results clearly show strain- and time-dependent effects of cyclic 20 mechanical load on CFs modulation of proliferation. $2 \%$ strain consistently elevated the 21 percentage of mitotic $\left(\mathrm{PHH}^{+}\right)$cells at the two stimulation times. This coincided with a 22 significant increase of $\mathrm{EdU}^{+}$cells at $72 \mathrm{~h}$ and a net increase in cell density at the same time 23 point (Fig 4). Conversely, $8 \%$ strain led to a similar response only after $24 \mathrm{~h}$, followed by a 24 rapid $\mathrm{PHH} 3$ drop at $72 \mathrm{~h}$. This event was neither accompanied by an increment in EdU uptake 25 nor by a net increase of cells compared to the controls. Contact inhibition of proliferation did 
1 not play a role in time-dependent proliferation dynamics as shown by cell density analyses

2 (Fig. 4H and Fig. 5). In addition, it is worth noting that time-dependent proliferation changes

3 were not considered in previous cyclic strain experiments on rat CFs, in which the applied

4 stimuli lasted from 4h (Dalla Costa et al., 2010) to a maximum of 24h (Atance et al., 2004;

5 Liao et al., 2004). Our findings therefore provide novel insights demonstrating a differential

6 response of human CFs to cyclic strain intensity involving stable or transient increase of cell

7 mitosis. The comparison of these findings relative to human-derived cells with previous

8 results on rat CFs proliferation under cyclic strain remains elusive, mainly due to the different

9 stimuli employed by different studies: decreased proliferation occurred when rat CFs were

10 subject to 5\% uniaxial strain (Atance et al., 2004) and to equibiaxial strain (Liao et al., 2004,

11 no strain intensity reported; Butt and Bishop, 1997, 20\% maximum strain); increased

12 proliferation occurred when rat CFs were subject to biaxial strain (Dalla Costa et al., 2010, no

13 strain intensity reported). However, it is worth noting that cardiac remodeling events have

14 been shown to retain distinctive and species-specific features (Dewald et al., 2004).

15 It is of interest to compare cell morphologies and proliferation rates exhibited by CFs in

16 the two strain stimulation regimes. Indeed, an elongated cell shape has been found to

17 negatively regulate cell proliferation especially when the nuclear shape is affected (Thakar et

18 al., 2009; Roca-Cusachs et al., 2008; Versaevel et al., 2012). Consistent with this, our data

19 show that the decrease in the percentage of $\mathrm{PHH}^{+}$cells at $72 \mathrm{~h}(8 \%$ strain $)$ coincided with a

20 consistent modification in nuclear and cell shape and with cell alignment. No late inhibition

21 of the proliferative response occurred in $2 \%$ cyclic strain conditions, where no significant

22 changes in nuclear morphology or cell alignment were detected. Nuclear shape indexes of

23 cells positive or negative to EdU were also analyzed and no significant differences were

24 found (Supplementary Material S5). Deeper investigations are therefore required to 
1 demonstrate and elucidate the relations between cell-shape and the strain-induced control and 2 modulation of human CFs proliferation.

3 To gain some insight into possible interactions between mechano-sensing and 4 modulation of proliferation, we explored the activation and translocation of YAP. 5 Interestingly, Codelia, et al., showed that applying cyclic strain $(20 \%, 1 \mathrm{~Hz}, 6 \mathrm{~h}$ duration $)$ to an 6 epithelial cell line resulted in increased cell proliferation mediated by YAP activation and 7 translocation in the nucleus (Codelia et al., 2013). Our results show a consistent reallocation 8 of YAP from cytoplasm to the nucleus in both $2 \%$ and $8 \%$ strain conditions after $72 \mathrm{~h}$ of 9 stimulus (Fig. 6). While this nuclear reallocation is in line with the recently highlighted role 10 of YAP in cell mechano-sensing, the time-dependent restrained proliferation of CFs after $72 \mathrm{~h}$ 11 at $8 \%$ strain also suggests that YAP nuclear localization may indeed act independently from 12 proliferation control or may be not sufficient by itself to elicit a continuous and sustained 13 strain-induced proliferation. In summary, the results here shown pave the way for further 14 studies into the regulation of strain-induced proliferation and highlight the importance of 15 time-dependent effects on mechano-sensing and modulation of proliferation.

16 V. CONCLUSIONS

17 In this work we have designed, developed and employed a microdevice for application 18 of uniform and uniaxial cyclic strain to cell monolayers. We designed this device specifically 19 to minimize the number of cells required and to increase throughput and ease of use. We 20 characterized the strain applied and then employed the microdevice to investigate biological 21 responses of human heart-derived adult CFs to cyclic strain. Mechanical load-dependent 22 effects on CFs proliferation were observed with significant proliferation increase under strain 23 intensities (2\%) representative of reduced myocardial contractility, whereas a more moderate, 24 time-dependent proliferative behavior occurred under more physiological strain intensities 25 (8\%). These findings suggest the existence of a cellular control of CFs proliferative behavior 
1 that acts with a dependency on the amount of the sensed mechanical stimulus and that could

2 be involved in the pathological evolution of cardiac fibrotic disease.

3

4 ACKNOWLEDGMENTS

5 This research was partially supported by Fondazione Cariplo, grant no. 2012-0891. The

6 Laboratory bench-fee, the costs for cell biology reagents and the use of fluorescence/confocal

7 microscope platforms was supported by Institutional funding (Ricerca Corrente) by Centro

8 Cardiologico Monzino to the Tissue Engineering Research Unit (MP). Microstructured

9 silicon wafers were fabricated at SMART ByoSYM (AP, RK). All authors declare no conflict 10 of interest.

11

12 AUTHORS CONTRIBUTIONS

13 MR conceived microfluidic platform design. MR, AP and GBF developed and preliminarily 14 validated the devices. GSU fabricated and characterized the devices. GSU and RS extracted 15 and expanded human heart-derived cardiac fibroblasts. GSU, MP and MS designed biological 16 experiments. GSU performed experiments. GSU and MP performed the imaging. GSU, GBF 17 and MS performed the data analyses. All authors discussed the results. GSU, MP and MS 18 wrote the manuscript. All authors reviewed the manuscript.

20 References:

21 Agocha AE, Eghbali-Webb M. 1997. A simple method for preparation of cultured cardiac 22 fibroblasts from adult human ventricular tissue. Mol. Cell. Biochem. 172:195-198.

23 Almaas VM, Haugaa KH, Strøm EH, Scott H, Smith H-J, Dahl CP, Geiran OR, Endresen K, 24 Aakhus S, Amlie JP, Edvardsen T. 2014. Noninvasive assessment of myocardial fibrosis 
1 in patients with obstructive hypertrophic cardiomyopathy. Heart 100:631-8.

2 http://www.ncbi.nlm.nih.gov/pubmed/24368281.

3 Ao M, Brewer BM, Yang L, Franco Coronel OE, Hayward SW, Webb DJ, Li D. 2015.

4 Stretching Fibroblasts Remodels Fibronectin and Alters Cancer Cell Migration. Sci. Rep.

$5 \quad$ 5:8334. http://dx.doi.org/10.1038/srep08334.

6 Aragona M, Panciera T, Manfrin A, Giulitti S, Michielin F, Elvassore N, Dupont S, Piccolo S.

7 2013. A mechanical checkpoint controls multicellular growth through YAP/TAZ

8 regulation by actin-processing factors. Cell 154:1047-1059.

9 Atance J, Yost MJ, Carver W. 2004. Influence of the extracellular matrix on the regulation of 10 cardiac fibroblast behavior by mechanical stretch. J. Cell. Physiol. 200:377-386.

11 Berk BC, Fujiwara K, Lehoux S. 2007. ECM remodeling in hypertensive heart disease. $J$. $12 \quad$ Clin. Invest. 117:568-575.

13 Butt RP, Bishop JE. 1997. Mechanical load enhances the stimulatory effect of serum growth 14 factors on cardiac fibroblast procollagen synthesis. J. Mol. Cell. Cardiol. 29:1141-1151.

15 Carver W, Nagpal ML, Nachtigal M, Borg TK, Terracio L. 1991. Collagen expression in 16 mechanically stimulated cardiac fibroblasts. Circ. Res. 69:116-122.

17 Codelia V, Sun G, Irvine K. 2013. Regulation of YAP by Mechanical Strain through Jnk and 18 Hippo Signaling. Curr. Biol. 24:2012-2017.

19 Colombo A, Cahill PA, Lally C. 2008. An analysis of the strain field in biaxial Flexcell 20 membranes for different waveforms and frequencies. Proc. Inst. Mech. Eng. H.

$21 \quad 222: 1235-1245$. 
1 Cosentino S, Castiglioni L, Colazzo F, Nobili E, Tremoli E, Rosa P, Abbracchio MP, Sironi

2 L, Pesce M. 2014. Expression of dual nucleotides/cysteinyl-leukotrienes receptor

3 GPR17 in early trafficking of cardiac stromal cells after myocardial infarction. J. Cell.

$4 \quad$ Mol. Med. 18(9):1785-96.

5 Curtis MW, Russell B. 2011. Micromechanical regulation in cardiac myocytes and

6 fibroblasts: Implications for tissue remodeling. Pflugers Arch. Eur. J. Physiol. 462:105-

$7 \quad 117$

8 Dalla Costa AP, Clemente CFMZ, Carvalho HF, Carvalheira JB, Nadruz W, Franchini KG.

9 2010. FAK mediates the activation of cardiac fibroblasts induced by mechanical stress

10 through regulation of the mTOR complex. Cardiovasc. Res. 86:421-431.

11 Dewald O, Ren G, Duerr GD, Zoerlein M, Klemm C, Gersch C, Tincey S, Michael LH,

12 Entman ML, Frangogiannis NG. 2004. Of mice and dogs: species-specific differences in

13 the inflammatory response following myocardial infarction. Am. J. Pathol. 164:665-677.

14 Donekal S, Venkatesh BA, Liu YC, Liu CY, Yoneyama K, Wu CO, Nacif M, Gomes AS,

15 Hundley WG, Bluemke DA, Lima JAC. 2014. Interstitial fibrosis, left ventricular

16 remodeling, and myocardial mechanical behavior in a population-based multiethnic

17 cohort: The multi-ethnic study of atherosclerosis (mesa) study. Circ. Cardiovasc.

$18 \quad$ Imaging 7:292-302.

19 Dupont S, Morsut L, Aragona M, Enzo E, Giulitti S, Cordenonsi M, Zanconato F, Le Digabel

20 J, Forcato M, Bicciato S, Elvassore N, Piccolo S. 2011. Role of YAP/TAZ in

21 mechanotransduction. Nature 474:179-183. 
1 Eghbali M. 1992. Cardiac fibroblasts: function, regulation of gene expression, and

$2 \quad$ phenotypic modulation. Basic Res. Cardiol. 87 Suppl 2:183-189.

3 Fan D, Takawale A, Lee J, Kassiri Z. 2012. Cardiac fibroblasts, fibrosis and extracellular

$4 \quad$ matrix remodeling in heart disease. Fibrogenesis Tissue Repair. 5:15.

5 Gambini E, Pompilio G, Biondi A, Alamanni F, Capogrossi MC, Agrifoglio M, Pesce M.

6 2011. C-kit+ cardiac progenitors exhibit mesenchymal markers and preferential

$7 \quad$ cardiovascular commitment. Cardiovasc. Res. 89:362-373.

8 Garot J, Bluemke DA, Osman NF, Rochitte CE, McVeigh ER, Zerhouni EA, Prince JL, Lima

9 JA. 2000. Fast determination of regional myocardial strain fields from tagged cardiac

10 images using harmonic phase MRI. Circulation 101:981-988.

11 Vande Geest JP, Di Martino ES, Vorp DA. 2004. An analysis of the complete strain field

12 within Flexercell membranes. J. Biomech. 37:1923-1928.

13 Gerstmair A, Fois G, Innerbichler S, Dietl P, Felder E. 2009. A device for simultaneous live

14 cell imaging during uni-axial mechanical strain or compression. J. Appl. Physiol.

$15 \quad$ 107:613-620.

16 Gorcsan J, Tanaka H. 2011. Echocardiographic assessment of myocardial strain. J. Am. Coll.

$17 \quad$ Cardiol. 58:1401-1413.

18 Gupta V, Grande-Allen KJ. 2006. Effects of static and cyclic loading in regulating

19 extracellular matrix synthesis by cardiovascular cells. Cardiovasc. Res. 72:375-83.

20 http://www.ncbi.nlm.nih.gov/pubmed/17010955. 
1 Heallen T, Zhang M, Wang J, Bonilla-Claudio M, Klysik E, Johnson RL, Martin JF. 2011.

2 Hippo pathway inhibits Wnt signaling to restrain cardiomyocyte proliferation and heart 3 size. Science 332:458-461.

4 Huang L, Mathieu PS, Helmke BP. 2010. A stretching device for high-resolution live-cell imaging. Ann. Biomed. Eng. 38:1728-1740.

6 Huang Y, Nguyen N-T, Lok KS, Lee PPF, Su M, Wu M, Kocgozlu L, Ladoux B. 2013. Nanomedicine (Lond). 8:543-53. http://www.ncbi.nlm.nih.gov/pubmed/23560406.

9 Huh D, Matthews BD, Mammoto A, Montoya-Zavala M, Hsin HY, Ingber DE. 2010.

10 Reconstituting organ-level lung functions on a chip. Science 328:1662-1668.

11 Husse B, Briest W, Homagk L, Isenberg G, Gekle M. 2007. Cyclical mechanical stretch 12 modulates expression of collagen I and collagen III by PKC and tyrosine kinase in 13 cardiac fibroblasts. Am. J. Physiol. Regul. Integr. Comp. Physiol. 293:R1898-R1907.

14 Krenning G, Zeisberg EM, Kalluri R. 2010. The origin of fibroblasts and mechanism of 15 cardiac fibrosis. J. Cell. Physiol. 225:631-37.

16 Kreutzer J, Ikonen L, Hirvonen J, Pekkanen-Mattila M, Aalto-Setälä K, Kallio P. 2014.

17 Pneumatic cell stretching system for cardiac differentiation and culture. Med. Eng. Phys.

$18 \quad 36: 496-501$.

19 Lee AA, Delhaas T, McCulloch AD, Villarreal FJ. 1999. Differential responses of adult 20 cardiac fibroblasts to in vitro biaxial strain patterns. J. Mol. Cell. Cardiol. 31:1833-43. 21 http://www.ncbi.nlm.nih.gov/pubmed/10525421. 
1 Liao XD, Wang XH, Jin HJ, Chen LY, Chen Q. 2004. Mechanical stretch induces

2 mitochondria-dependent apoptosis in neonatal rat cardiomyocytes and G2/M

3 accumulation in cardiac fibroblasts. Cell Res. 14:16-26.

4 Lindahl GE, Chambers RC, Papakrivopoulou J, Dawson SJ, Jacobsen MC, Bishop JE,

5 Laurent GJ. 2002. Activation of fibroblast procollagen ??1(I) transcription by

6 mechanical strain is transforming growth factor-??-dependent and involves increased

7 binding of CCAAT-binding factor (CBF/NF-Y) at the proximal promoter. J. Biol. Chem.

$8 \quad 277: 6153-6161$.

9 Liu F, Lagares D, Choi KM, Stopfer L, Marinkovic A, Vrbanac V, Probst CK, Hiemer SE,

10 Sisson TH, Horowitz JC, Rosas IO, Fredenburgh LE, Feghali-Bostwick C, Varelas X,

11 Tager AM, Tschumperlin DJ. 2015. Mechanosignaling through YAP and TAZ drives

12 fibroblast activation and fibrosis. Am. J. Physiol. Lung Cell. Mol. Physiol. 308:L344-57.

13 Lucas JA, Zhang Y, Li P, Gong K, Miller AP, Hassan E, Hage F, Xing D, Wells B, Oparil S,

14 Chen Y-F. 2010. Inhibition of transforming growth factor-beta signaling induces left

15 ventricular dilation and dysfunction in the pressure-overloaded heart. Am. J. Physiol.

$16 \quad$ Heart Circ. Physiol. 298:H424-H432.

17 Mackenna D, Summerour SR, Villarreal FJ. 2000. Role of mechanical factors in modulating

18 cardiac fibroblast function and extracellular matrix synthesis 46:257-263.

19 Moore-Morris T, Guimarães-Camboa N, Banerjee I, Zambon AC, Kisseleva T, Velayoudon

20 A, Stallcup WB, Gu Y, Dalton ND, Cedenilla M, Gomez-Amaro R, Zhou B, Brenner

21 DA, Peterson KL, Chen J, Evans SM. 2014. Resident fibroblast lineages mediate

22 pressure overload-induced cardiac fibrosis. J. Clin. Invest. 124:2921-2934.

John Wiley \& Sons 
1 Mosqueira D, Pagliari S, Uto K, Ebara M, Romanazzo S, Escobedo-Lucea C, Nakanishi J,

2 Taniguchi A, Franzese O, Di Nardo P, Goumans MJ, Traversa E, Pinto-Do-Ó P, Aoyagi

3 T, Forte G. 2014. Hippo pathway effectors control cardiac progenitor cell fate by acting

4 as dynamic sensors of substrate mechanics and nanostructure. ACS Nano 8:2033-2047.

5 Neidlinger-Wilke C, Grood E, Claes L, Brand R. 2002. Fibroblast orientation to stretch

6 begins within three hours. J. Orthop. Res. 20:953-956.

7 Neuss M, Regitz-Zagrosek V, Hildebrandt A, Fleck E. 1996. Isolation and characterisation of

8 human cardiac fibroblasts from explanted adult hearts. Cell Tissue Res 286:145-153.

9 http://www.ncbi.nlm.nih.gov/pubmed/8781221.

10 Papizan JB, Olson EN. 2014. Hippo in the path to heart repair. Circ. Res. 3:332-34

11 Pavesi A, Adriani G, Rasponi M, Zervantonakis I, Fiore G, Kamm R. 2015. Controlled

12 electromechanical cell stimulation on-a-chip. Sci. Rep. 5:11800.

13 Porter KE, Turner NA. 2009. Cardiac fibroblasts: At the heart of myocardial remodeling.

14 Pharmacol. Ther.123:255-78.

15 Roca-Cusachs P, Alcaraz J, Sunyer R, Samitier J, Farré R, Navajas D. 2008. Micropatterning

16 of single endothelial cell shape reveals a tight coupling between nuclear volume in G1

17 and proliferation. Biophys. J. 94:4984-4995.

18 Rossini A, Zacheo A, Mocini D, Totta P, Facchiano A, Castoldi R, Sordini P, Pompilio G, 19 Abeni D, Capogrossi MC, Germani A. 2008. HMGB1-stimulated human primary 20 cardiac fibroblasts exert a paracrine action on human and murine cardiac stem cells. $J$. 21 Mol. Cell. Cardiol. 44:683-693. 
1 Ruwhof C, van Wamel AE, Egas JM, van der Laarse A. 2000. Cyclic stretch induces the

2 release of growth promoting factors from cultured neonatal cardiomyocytes and cardiac

3 fibroblasts. Mol. Cell. Biochem. 208:89-98.

4 Ruwhof C, Van Der Laarse A. 2000. Mechanical stress-induced cardiac hypertrophy:

5 Mechanisms and signal transduction pathways. Cardiovasc. Res.208:89-98

6 Sadoshima J, Izumo S. 1997. The cellular and molecular response of cardiac myocytes to

7 mechanical stress. Annu. Rev. Physiol. 59:551-571.

8 Schroer AK, Merryman WD. 2015. Mechanobiology of myofibroblast adhesion in fibrotic

$9 \quad$ cardiac disease. J. Cell Sci. 128:1865-1875.

10 Shao Y, Tan X, Novitski R, Muqaddam M, List P, Williamson L, Fu J, Liu AP. 2013.

11 Uniaxial cell stretching device for live-cell imaging of mechanosensitive cellular

12 functions. Rev. Sci. Instrum. 84: 114304.

13 Shimizu K, Shunori A, Morimoto K, Hashida M, Konishi S. 2011. Development of a biochip

14 with serially connected pneumatic balloons for cell-stretching culture. Sensors Actuators,

15 B Chem. 156:486-493.

16 Shyu K-G. 2009. Cellular and molecular effects of mechanical stretch on vascular cells and

17 cardiac myocytes. Clin. Sci. (Lond). 116:377-89.

18 http://www.ncbi.nlm.nih.gov/pubmed/19175356.

19 Simmons CS, Sim JY, Baechtold P, Gonzalez A, Chung C, Borghi N, Pruitt BL. 2011.

20 Integrated strain array for cellular mechanobiology studies. J. Micromechanics

$21 \quad$ Microengineering. 21:54016-54025.

John Wiley \& Sons 
1 Souders CA, Bowers SLK, Baudino TA. 2009. Cardiac fibroblast: The renaissance cell. Circ. $2 \quad$ Res. 105:1164-1176.

3 Terracio L, Miller B, Borg TK. 1988. Effects of cyclic mechanical stimulation of the cellular 4 components of the heart: in vitro. In Vitro Cell. Dev. Biol. 24:53-58.

5 Thakar RG, Cheng Q, Patel S, Chu J, Nasir M, Liepmann D, Komvopoulos K, Li S. 2009.

6 Cell-shape regulation of smooth muscle cell proliferation. Biophys. J. 96:3423-3432.

7 Tomasek JJ, Gabbiani G, Hinz B, Chaponnier C, Brown RA. 2002. Myofibroblasts and 8 mechano-regulation of connective tissue remodelling. Nat. Rev. Mol. Cell Biol. 3:3499363.

10 Tremblay D, Chagnon-Lessard S, Mirzaei M, Pelling AE, Godin M. 2014. A microscale 11 anisotropic biaxial cell stretching device for applications in mechanobiology. Biotechnol. 12 Lett. 36:657-665.

13 Versaevel M, Grevesse T, Gabriele S. 2012. Spatial coordination between cell and nuclear 14 shape within micropatterned endothelial cells. Nat. Commun. 3:671.

15 Wang D, Xie Y, Yuan B, Xu J, Gong P, Jiang X. 2010. A stretching device for imaging real-

16 time molecular dynamics of live cells adhering to elastic membranes on inverted

17 microscopes during the entire process of the stretch. Integr. Biol. (Camb). 2:288-293.

18 Wang Q, Zhang X, Zhao Y. 2013. Micromechanical stimulator for localized cell loading:

19 fabrication and strain analysis. J. Micromechanics Microengineering 23:015002.

20 Watson CJ, Phelan D, Collier P, Horgan S, Glezeva N, Cooke G, Xu M, Ledwidge M, 21 McDonald K, Baugh JA. 2014. Extracellular matrix sub-types and mechanical stretch 
1 impact human cardiac fibroblast responses to transforming growth factor beta. Connect.

2 Tissue Res. 55:248-256.

3 Watson CJ, Phelan D, Xu M, Collier P, Neary R, Smolenski A, Ledwidge M, McDonald K,

4 Baugh J. 2012. Mechanical stretch up-regulates the B-type natriuretic peptide system in

5 human cardiac fibroblasts: a possible defense against transforming growth factor- $\beta$

6 mediated fibrosis. Fibrogenesis Tissue Repair. 5:9

7 Xin M, Kim Y, Sutherland LB, Murakami M, Qi X, McAnally J, Porrello ER, Mahmoud AI,

8 Tan W, Shelton JM, Richardson J a, Sadek H a, Bassel-Duby R, Olson EN. 2013. Hippo

9 pathway effector Yap promotes cardiac regeneration. Proc. Natl. Acad. Sci. U. S. A.

$10 \quad$ 110:13839-44.

11 Yamazaki T, Komuro I, Yazaki Y. 1995. Molecular mechanism of cardiac cellular

12 hypertrophy by mechanical stress. J. Mol. Cell. Cardiol. 27:133-140.

13 Yost MJ, Simpson D, Wrona K, Ridley S, Ploehn HJ, Borg TK, Terracio L. 2000. Design and

14 construction of a uniaxial cell stretcher. Am. J. Physiol. Heart Circ. Physiol.

15 279:H3124-H3130.

16 Zeisberg EM, Kalluri R. 2010. Origins of cardiac fibroblasts. Circ. Res. 107:1304-1312.

17

18

19

20

21

John Wiley \& Sons 


\section{Figure Legends}

Figure 1 - A) Annotated cross section of a stretching unit: geometric parameters are highlighted $\left(W_{a}\right.$ : side chamber width, $W_{c}$ : culture chamber width, $h$ : culture chamber height, $m$ : membrane thickness, $t:$ wall thickness). Cell culture chamber is represented in blue, side actuation chambers are represented in red and lower fluidic circuit is represented in green. B) Top view of microdevice layers layout: top layer features culture chambers (blue), actuation circuit and chambers (red), bottom layer features common lower fluidic circuit (green) and lower halves of the side actuation chambers (red). C) A fabricated microdevice filled with colored dyes. Same color code as Panels $A$ and $B$.

Figure $2-A$ ) Average strain intensity as a function of vacuum pressures. The relationship is nearly linear with a peak strain intensity of $8 \%$ at $-600 \mathrm{mmHg}, n=10$. B) Strain field spatial characterization carried out by tracking graphite particles displacements. Color maps represent the strain field computed in the $x x$ and $y y$ directions by Digital Image Correlation algorithms applied to two representative images taken at $-500 \mathrm{mmHg}$. The strain field results uniform and uniaxial. Histograms represent mean values of $x x$ and yy strain component obtained from computed $2 D$ maps ( $n=3$ microdevices). Values were extracted from 9 regions along channel length (x-axis) and 3 regions (top, center, bottom) along channel width (y-axis). One-way ANOVA with Bonferroni post-hoc tests were performed to identify regions with variations on the strain field $\left({ }^{*}=p<0.05\right) C$ ) Top-view of a culture chamber showing the region mapped for $2 D$ strain maps generation (dashed black line) and the effective area of controlled strain, not taking into account lateral regions with excursions in xx strain component (white hatch pattern).

Figure 3 - Cell morphology analyses. Representative images of human CFs stained for DAPI (blue) and Phalloidin (red) after $24 \mathrm{~h}(A)$ and $72 \mathrm{~h}(B)$ of control, $2 \%$ strain and $8 \%$ strain culture condition. Strain direction is indicated with white arrows. Bar graphs in panels $A$ and B show frequency distributions of nuclear angles (bin width $=20^{\circ}$ ) of corresponding representative images. Panel $C$ shows calculations of cell area. Cells significantly increase their size only in control conditions. No increase in size is reported for either $2 \%$ or $8 \%$ strain conditions. Panel D shows cell shape index. Cell shape becomes elongated, increasingly with increasing strain intensity. Panel E shows nuclear shape index. A significant elongation of nuclear shape is reported only after $72 \mathrm{~h}$ of $8 \%$ strain. Panel $F$ shows the fraction of aligned cells per condition. Cells considered aligned are the ones showing an angle of $0^{\circ} \pm 10^{\circ}$ with the horizontal axis. Significant alignment along the horizontal axis occurs only after 72 hours of $8 \%$ cyclic strain. Scale bars $=75 \mu \mathrm{m}$. All conditions $n=6$ minimum. All comparisons analyzed with Kruskal-Wallis statistical tests except Cell and Nuclear Shape index analyses performed with one-way ANOVA tests with Dunnet's post-hoc comparisons. $\quad *=p<0.05, \quad * *=p<0.01, \quad * * *=p<0.001$, $* * * *=p<0.0001$. Bar graphs color code: grey bars indicate control, orange bars indicate $2 \%$ strain and red bars indicate $8 \%$ strain.

Figure 4 - Cell proliferation analyses. A) Images of human CFs fixed after $72 \mathrm{~h}$ of control, 2\% strain or 8\% strain conditions and stained for DAPI (nuclei, blue) and Ki67 (whole cell cycle, pink). B) Expression of Ki67 in all conditions. No significant change is reported. C) Images of DAPI (blue) and EdU (S-phase, white) incorporation stainings after 72h. D) Expression of EdU in all conditions. Increased DNA synthesis is reported for $2 \%$ strain after $72 h . E, G$ ) Images of DAPI and PHH3 (mitotic phase, green) stainings after $24 h(E)$ and $72 h$ $(G) . F)$ Expression of PHH3 in all conditions. A significant increase in cell mitosis is reported for $2 \%$ strain at all time-points and for $8 \%$ strain only after 24h. H) Cell density calculated from nuclei counts. Cells significantly increase their density after $72 \mathrm{~h}$ of $2 \%$ strain. All conditions $n=4$ minimum. Scale bars $=75 \mu \mathrm{m}$. All comparisons analyzed with Kruskal-Wallis tests except Cell Density data analyzed with One-way ANOVA with Dunnet's post-hoc comparisons. ${ }^{*}=p>0.05, * *=p<0.01$. Bar graphs color code: grey bars indicate control, orange bars indicate $2 \%$ strain and red bars indicate $8 \%$ strain.

Figure 5 - Expression of EdU with respect to cell density values. Linear fits were calculated for control $\left(R^{2}=0.49\right), 2 \%$ strain $\left(R^{2}=0.73\right)$ and $8 \%$ strain $\left(R^{2}=0.49\right)$ conditions and analysis of covariance tests (ANCOVA) were performed to determine if slopes and intercepts were significantly different between conditions. We found that slopes did not differ significantly between all three conditions, whereas intercept of $2 \%$ strain linear fit is significantly higher than control and $8 \%$ strain linear fits ( $p=0.0063)$. Intercepts of $8 \%$ strain linear fit vs. control condition linear fit did not differ significantly. This further demonstrates the increased proliferative effect of $2 \%$ strain condition.

Figure 6 - YAP localization analyses. A) Images of human CFs fixed after $72 \mathrm{~h}$ of control, $2 \%$ strain or $8 \%$ strain conditions and stained for YAP (green). Scale bars $=50 \mu \mathrm{m}$. Bar graphs show the manual count of YAP positive nuclei $(B)$ and the quantitative nuclear fluorescence intensity calculations $(C) .2 \%$ and $8 \%$ strain similarly increase nuclear localization of YAP. All conditions $n=4$ minimum, Kruskal-Wallis test, ${ }^{* *}=p<0.01$. Grey bars indicate control, orange bars indicate $2 \%$ strain and red bars indicate $8 \%$ strain. 

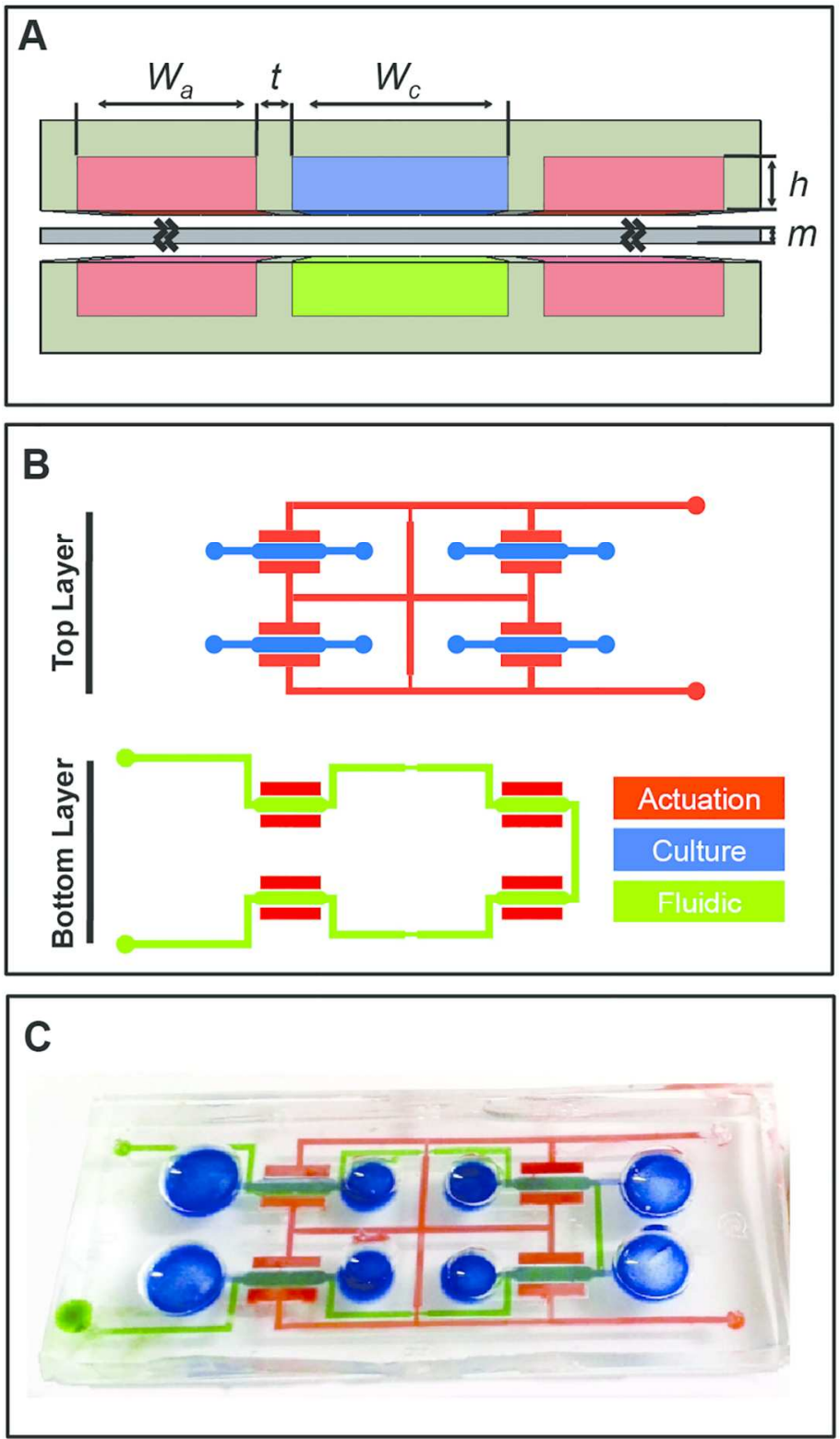

$143 \times 246 \mathrm{~mm}(300 \times 300 \mathrm{DPI})$ 

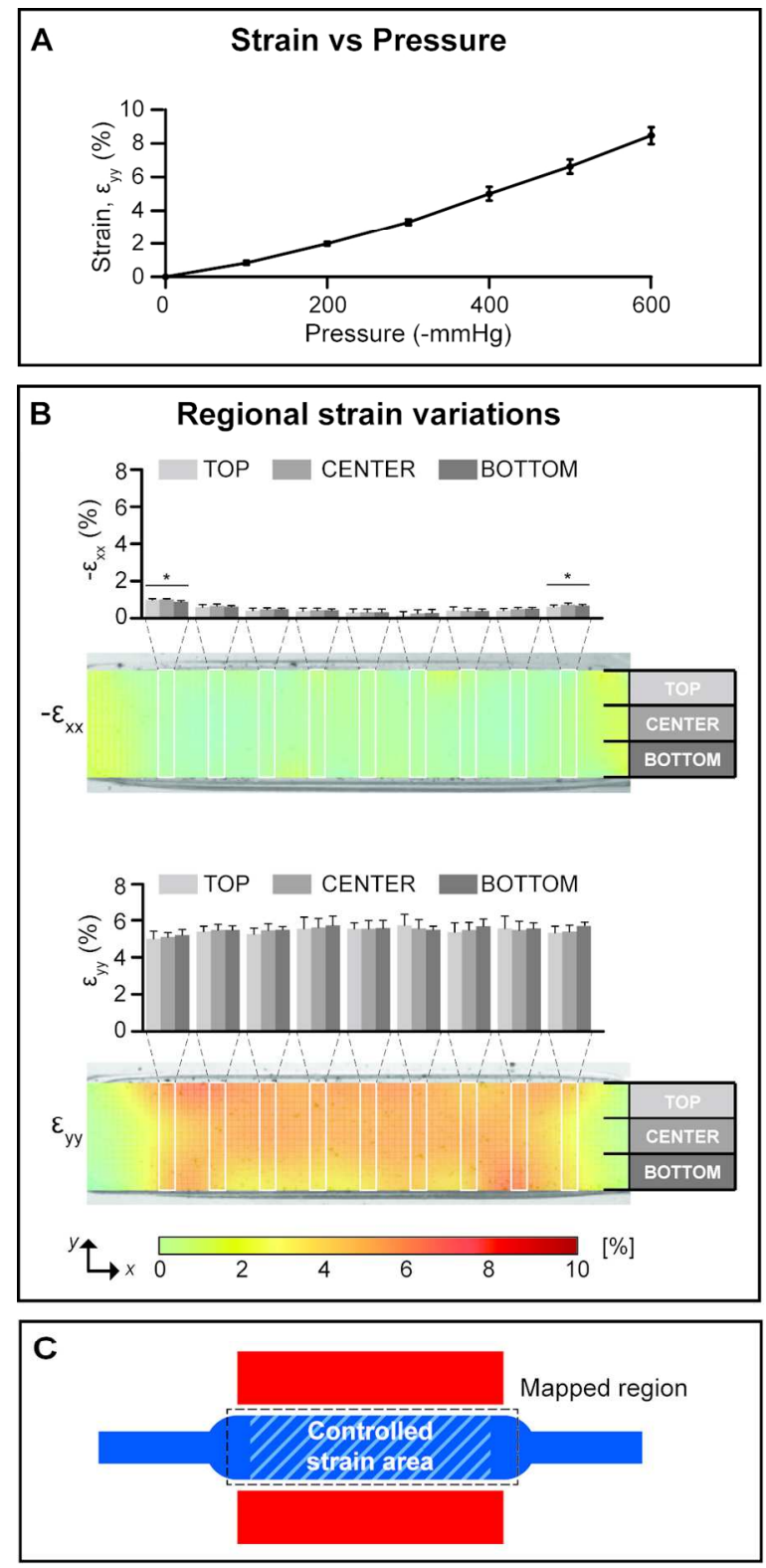

$83 \times 173 \mathrm{~mm}(300 \times 300$ DPI $)$ 

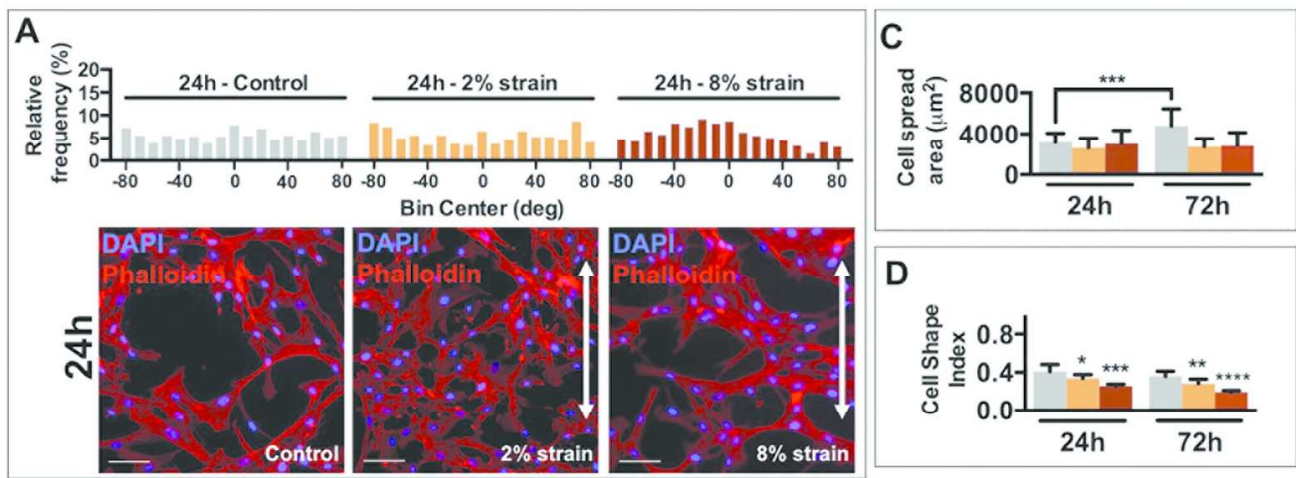

D
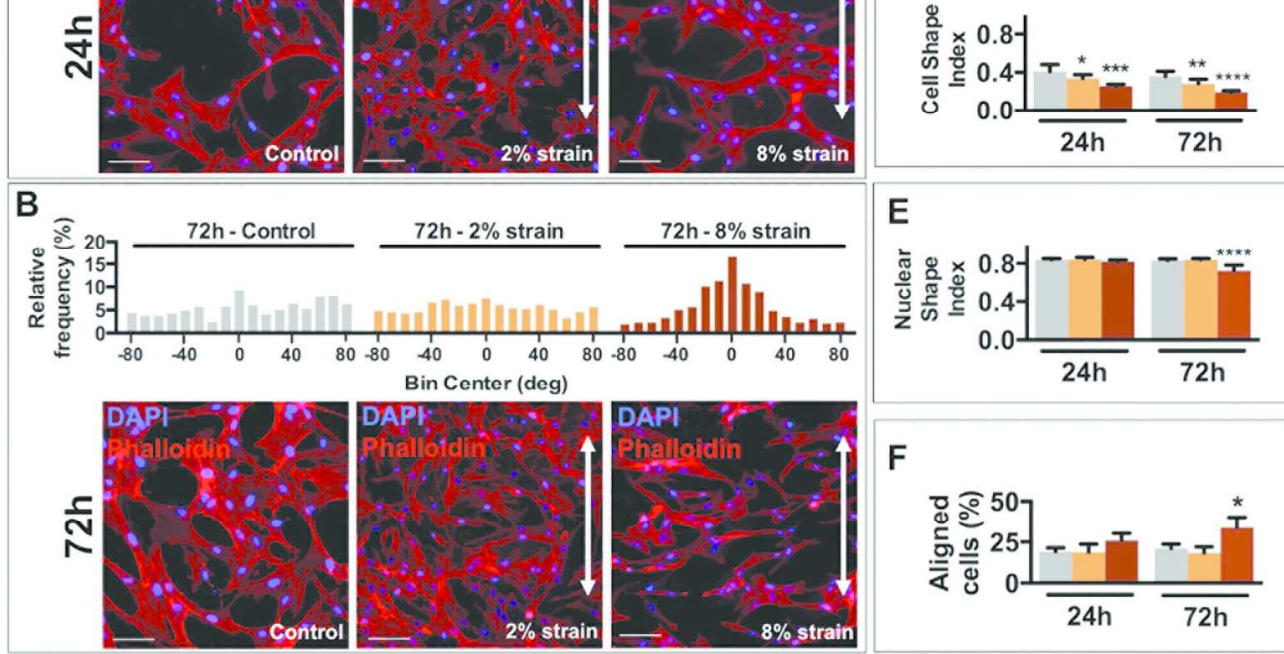

$171 \times 124 \mathrm{~mm}(300 \times 300 \mathrm{DPI})$ 

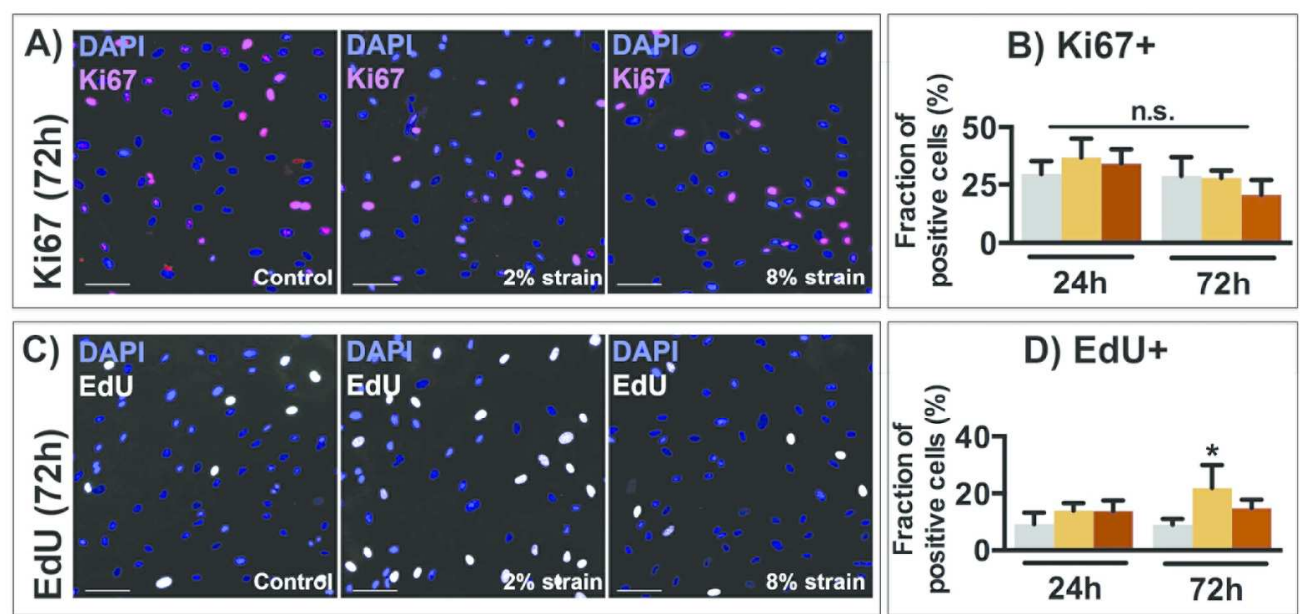

D) EdU+
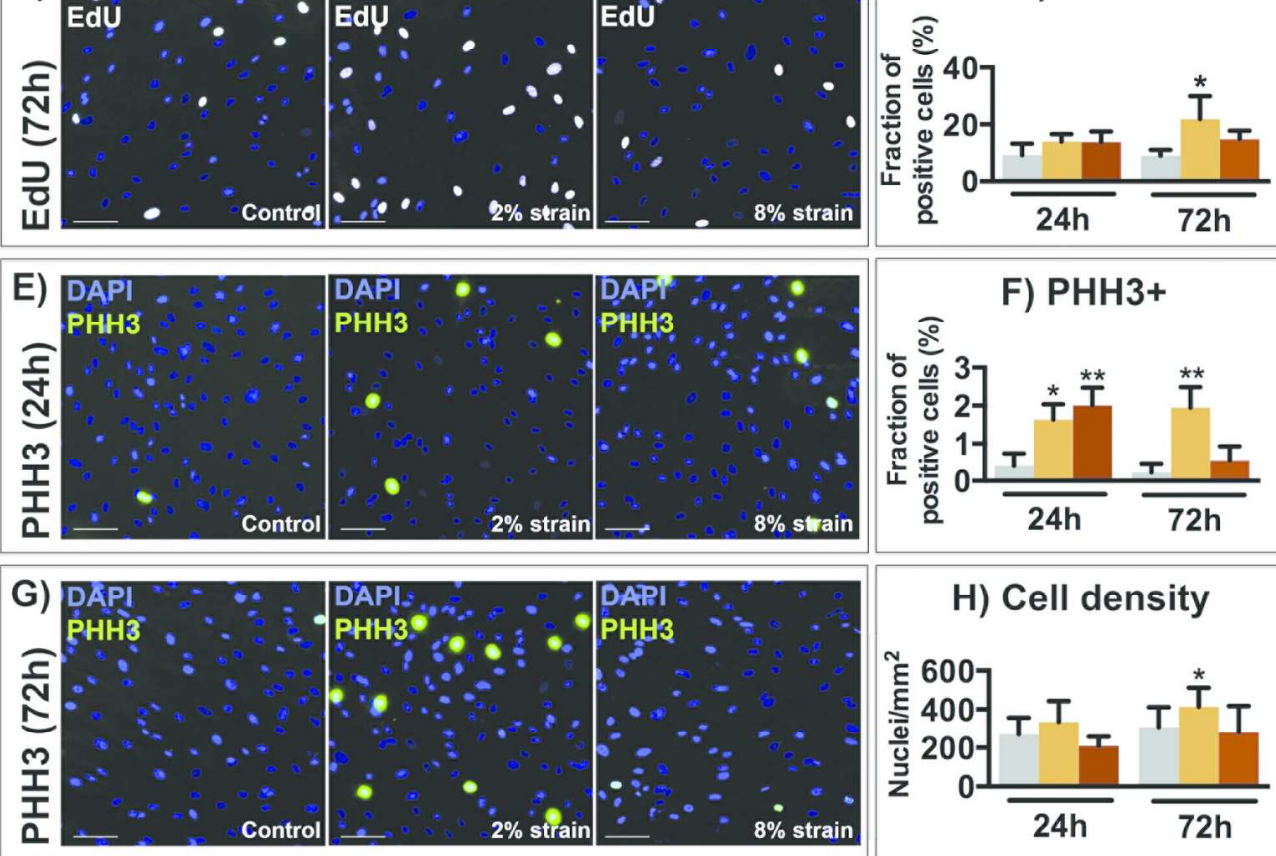

$171 \times 161 \mathrm{~mm}(300 \times 300 \mathrm{DPI})$

H) Cell density

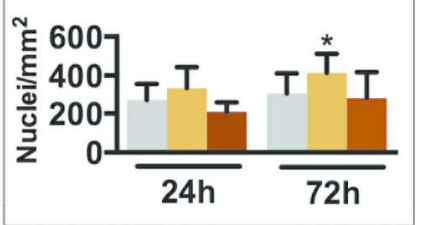




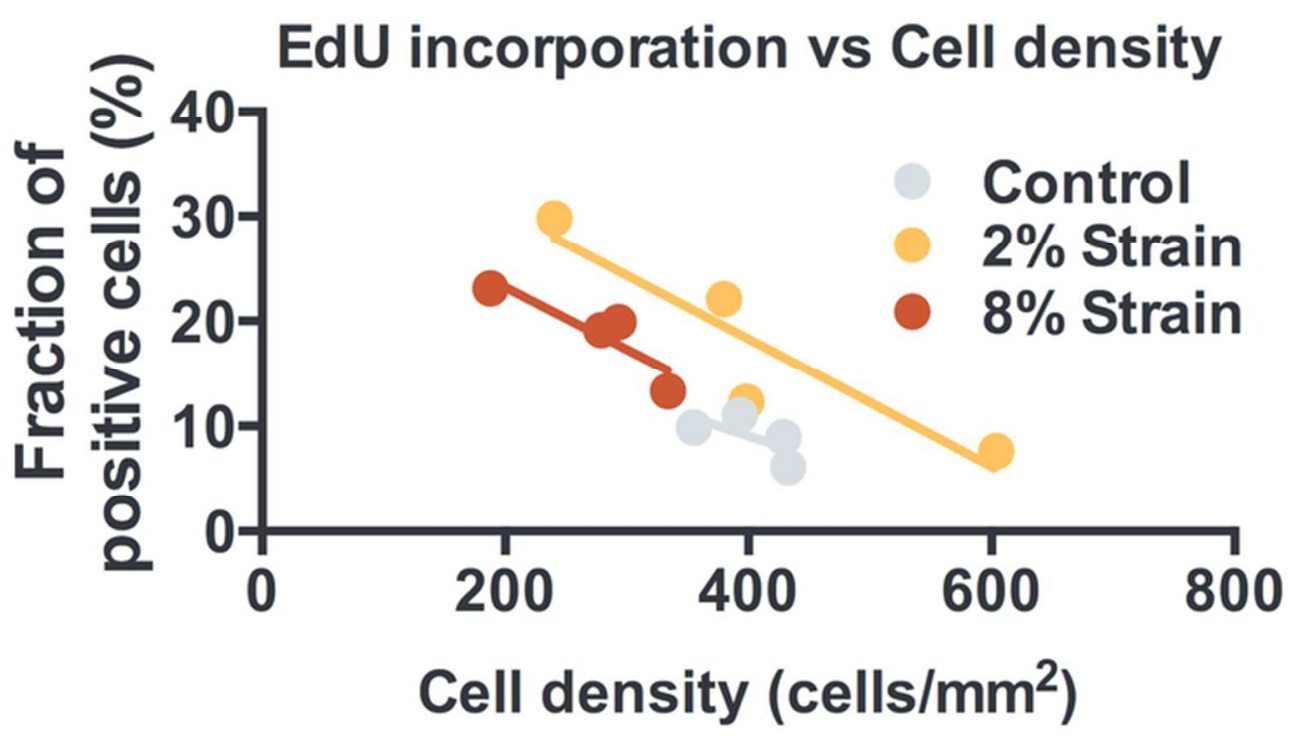

$63 \times 36 \mathrm{~mm}(300 \times 300$ DPI $)$ 

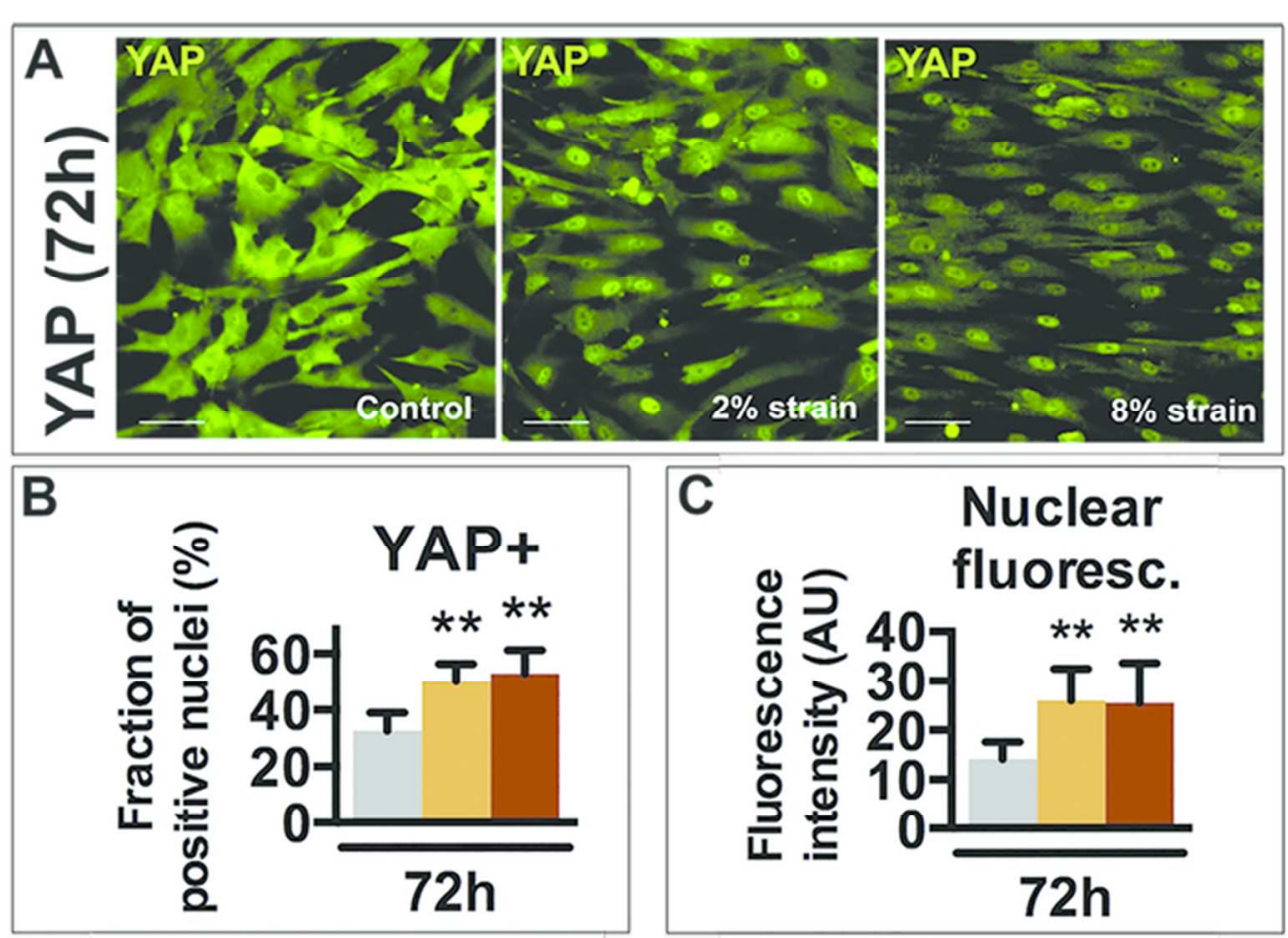

$60 \times 43 \mathrm{~mm}(300 \times 300$ DPI $)$ 


\section{Supplementary Materials}

Supplementary Material S1. FEM-aided stretching unit design. The design of the microdevice stretching unit was performed by pursuing two main design specifics: generate uniform membrane strain of around $8 \%$ and provide a cell culture region of more than $5 \mathrm{~mm}^{2}$. The geometric parameters involved into this design procedure were: membrane thickness (m), wall thickness (t), width of the culture (Wc) and actuation (Wa) chambers, length of the chambers (Lc) and chamber height (h). Width (Wc) and length (Lc) of the culture chambers were set respectively to $1.2 \mathrm{~mm}$ and $5 \mathrm{~mm}$. The chamber height $(\mathrm{h})$ was set to $300 \mu \mathrm{m}$. A membrane thickness of $80 \mu \mathrm{m}$ was chosen to avoid membrane sagging and non-uniformities in membrane planarity. Width of the actuation chambers (Wa) was set to $1 \mathrm{~mm}$ to allow for complete wall displacement. Given this geometry, the effect of wall thickness on membrane strain was evaluated by numerical simulation of the $2 \mathrm{D}$ cross-sectional geometry of the stretching unit. Three 2D models of the cross-section of the device were designed with the Solid Mechanics module of Comsol Multiphysics 4.3 (Comsol, Inc., Burlington, MA). Each model comprised the culture chamber, the lower fluidic chamber and the side actuation chambers and featured a different wall thickness (namely $\mathrm{t}_{1}=100 \mu \mathrm{m}, \mathrm{t}_{2}=200 \mu \mathrm{m}, \mathrm{t}_{3}=300 \mu \mathrm{m}$ ). The model geometries were discretized with a mesh scheme consisting of triangular elements. A mesh sensitivity analysis was performed to determine the optimal number of elements and element size. To this aim, the displacement of two representative points on the culture membrane upon constant negative pressure applied to the side actuation chambers ($600 \mathrm{mmHg}$ ) was evaluated for increasingly fine mesh schemes. This parameter was found to reach an asymptotic value for a mesh scheme consisting of about 31000 elements featuring a maximum characteristic size of $15 \mu \mathrm{m}$. These mesh properties were employed for all three models. The material properties of Sylgard 184 PDMS were assigned to the models 
(specifically Young's modulus $=1.5 \mathrm{MPa}$ and Poisson's module $=0.499)$. Encastre boundary conditions were applied to the outer faces of the device cross-section. A uniform load resulting from a negative pressure of $-600 \mathrm{mmHg}$ was applied to both side chambers and a stationary study was solved.

Figure S1.1 shows the resulting deformed configuration and strain field intensity throughout the cross-sections in all three geometries. In all cases, the membrane strain resulted uniform along its width, while the strain intensity was inversely proportional to the wall thickness. Although the wall thickness of $t_{1}=100 \mu \mathrm{m}$ yielded maximum membrane strain (around 14\%), actual fabricated devices showed occasional leakage of culture medium from culture chambers to side actuation chambers upon application of negative pressure. We believed that leakage could be mainly due to the small surface available for the adhesion, and this geometry was therefore discarded. The geometry with wall thickness $t_{2}=200 \mu \mathrm{m}$ was then chosen as final geometry because of functional robustness and maximum strain field of $8 \%$. Final geometry parameters are shown in Table S1.2. 
Figure S1.1 - Resulting deformed configurations and strain field intensities throughout three different cross-sectional geometries. Wall thickness of $t_{1}=100 \mu \mathrm{m}$ results in membrane strain field of around $14 \%$, wall thickness of $t_{2}=200 \mu \mathrm{m}$ results in strain field of around $8 \%$ whereas wall thickness of $t_{3}=300 \mu \mathrm{m}$ results in a strain field of around $6 \%$

\begin{tabular}{c|c}
\hline $\begin{array}{c}\text { Microdevice geometric parameters } \\
\text { Geometric parameter }\end{array}$ & $\begin{array}{c}\text { Value } \\
(\boldsymbol{\mu m})\end{array}$ \\
\hline Chamber height $(h)$ & 300 \\
Culture chamber width $\left(W_{c}\right)$ & 1200 \\
Chamber length $(L c)$ & 5000 \\
Side actuation chamber width & 1000 \\
$\left(W_{a}\right)$ & \\
Wall thickness $(t)$ & 200 \\
\hline Membrane thickness $(m)$ & 80 \\
\hline
\end{tabular}

Table S1.2 - Details of microdevice geometry. The parameters are outlined in Figure 1 (main paper) and have been optimized to obtain a uniform strain of $8 \%$ on a culture membrane larger than $5 \mathrm{~mm}^{2}$. 
Supplementary Material S2. Fabrication of silicon master molds. Microdevices were realized through PDMS replica molding using microstructured silicon wafers as molds. Wafer preparation utilized deep reactive-ion etching (DRIE) technique to obtain structures featuring highly vertical-walled trenches and high aspect ratios. Briefly, 10" silicon wafers were first cleaned in a wet bench with piranha solution $(3: 1 \mathrm{v} / \mathrm{v}$ sulfuric acid and hydrogen peroxide) at $120^{\circ} \mathrm{C}$, rinsed with DI water and dried with nitrogen gas. To enhance adhesion, hexamethyldisilazane (HMDS) was spin-coated on wafers and allowed to dry at $100^{\circ} \mathrm{C}$. Positive photoresist (AZ9260) was then spin-coated on the wafers at $1200 \mathrm{rpm}$ for 30s to reach a target thickness of $22 \mu \mathrm{m}$ and baked on a hotplate at $114^{\circ} \mathrm{C}$ for 240 s. Layouts were transferred to the coated wafers by filtering UV light exposure (energy: $2,100 \mathrm{~mJ} / \mathrm{cm}^{2}$, hard contact mode: gap $25 \mu \mathrm{m})$ through corresponding photomasks. The physical masks were finally obtained by developing the wafers in AZ4100k and DI water solution $(1: 2, \mathrm{v} / \mathrm{v})$ for about 90s, rinsing with DI water and drying with nitrogen gas. The unmasked silicon surface was finally etched at a rate of $1 \mu \mathrm{m} / \mathrm{min}$. The positive tone photoresist was removed from the wafers through lift-off, prior to subsequent use as master molds.

\section{Supplementary Material S3. Isolation and expansion of human CFs from atrial samples.}

The atrial fragments were cut into about $1 \mathrm{~mm}^{3}$ pieces and incubated four times for $30 \mathrm{~min}$ at $37^{\circ} \mathrm{C}$ with $3 \mathrm{mg} / \mathrm{ml}$ collagenase NB4 (Serva, Germany). After digestion, the solution was filtered using $70 \mu \mathrm{m}$ mesh nylon filters and the resulting cells solution was plated onto uncoated Petri dishes. Culture medium was Ham's F12 medium (Lonza, Milan, Italy) containing 10\% FBS (Hyclone, USA), 2mM L-Glutathione (Sigma, Italy), 0.05\% Human Erythropoietin (Sigma, Italy), 10ng/ml bFGF (Peprotech, UK) and antibiotics. Cell cultures 
were incubated at $37^{\circ} \mathrm{C}$ and $5 \% \mathrm{CO}_{2}$ at all stages. Cells were amplified and then seeded for mechanical strain experiments at a passage number of 3 .

Supplementary Material S4. Generation of 2D strain field color maps. Full-field strains were calculated by using Improved Digital Correlation (DIC) tool for MATLAB (http://www.mathworks.com/matlabcentral/fileexchange/43073-improved-digital-imagecorrelation--dic-). Images were obtained from microdevices actuated with a pressure of $500 \mathrm{mmHg}$. Image correlation was performed on both reduced and full size images to improve tracking of large displacements. For reduced images, a reduction factor of 3, a grid step size of $20 \mathrm{px}$ and a subset size of $20 \mathrm{px}$ were employed. For full size images, a grid step size of $10 \mathrm{px}$ and a subset size of 20px were set. Displacements were then smoothened and strains calculated with the Cubic (16-node) algorithm. Color maps were generated from three different microdevices and are shown in Figure S2. Strain field uniaxiality and uniformity is consistent across different microdevices.

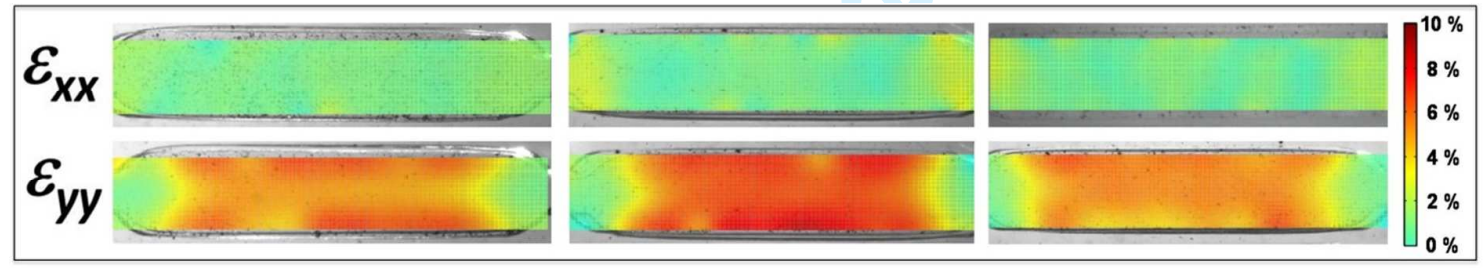

Figure S4 - Color maps of strain field intensity along $x x$ and yy directions for three different microdevices actuated with a pressure of $-500 \mathrm{mmHg}$. Strain field results uniaxial and uniform within different microdevices. 


\section{Supplementary Material S5. Correlation of YAP nuclear intensity and EdU expression with cell morphology parameters.}

In order to evaluate possible correlations between YAP translocation and cell morphology, or between cell proliferation and cellular morphology, we plotted YAP intensity values against cellular morphology parameter (cell spread area, cell shape index and nuclear shape index) and EdU expression against nuclear shape index. In addition we plotted cell shape index values against cell spread area.

Figure S5.1 shows correlations between Cell Shape Index and Cell spread area. No significant correlation is observed.

Figure S5.2 shows the distribution of Nuclear Shape Indexes in cells positive or negative to EdU in Control, $2 \%$ strain and $8 \%$ strain conditions. No significant differences are present within the compared groups.

Figure S5.3 shows correlations between YAP nuclear intensity and cell morphology parameters. It is of interest to note a possible correlation between cell spread area and YAP nuclear intensity: YAP nuclear intensity seems to increase with increasing cell spread area only in cells subjected to $72 \mathrm{~h}$ of $2 \%$ strain $\left(\mathrm{R}^{2}=0.45\right)$. 
Cell Shape Index vs Cell Area

CTRL

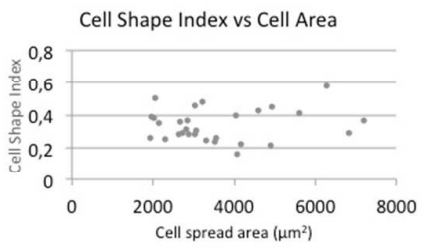

$2 \%$ strain

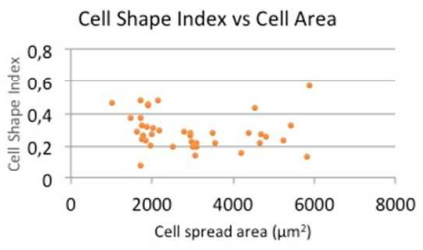

$8 \%$ strain

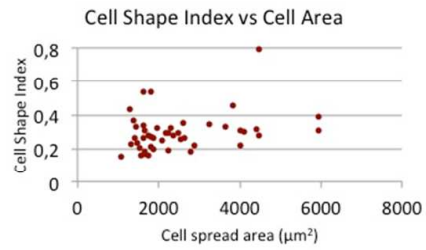

Figure S5.1 - Plots of Cell Shape Index values vs Cell area, at Control, 2\% strain or 8\% strain conditions

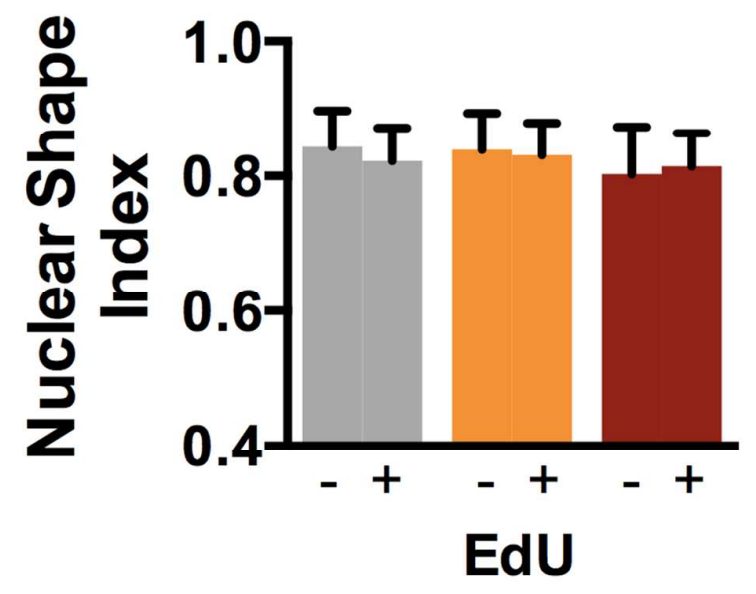

Figure S5.2 - Comparisons of Nuclear Shape Index values for cells positive or negative for EdU marker. No statistical significance is reported between proliferating and nonproliferating cells. 


\section{YAP nuclear intensity vs Cell morphology parameters CTRL \\ $2 \%$ strain}
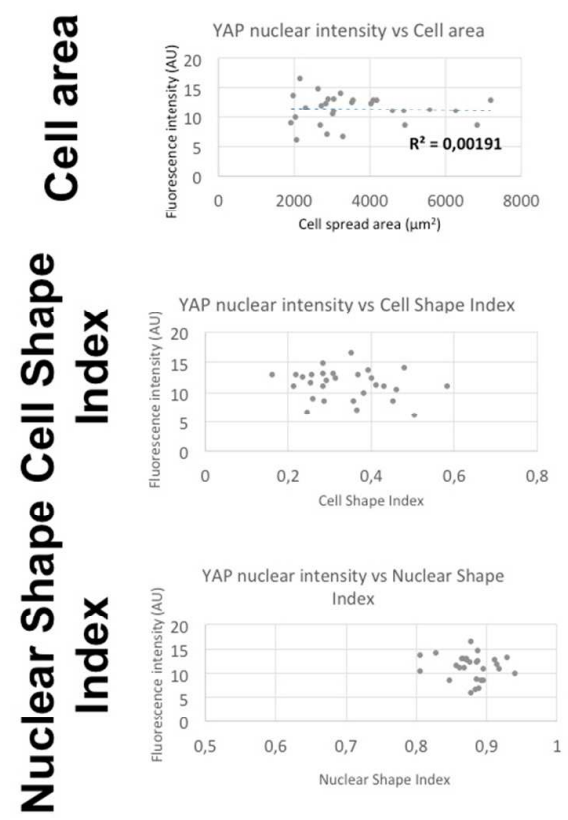
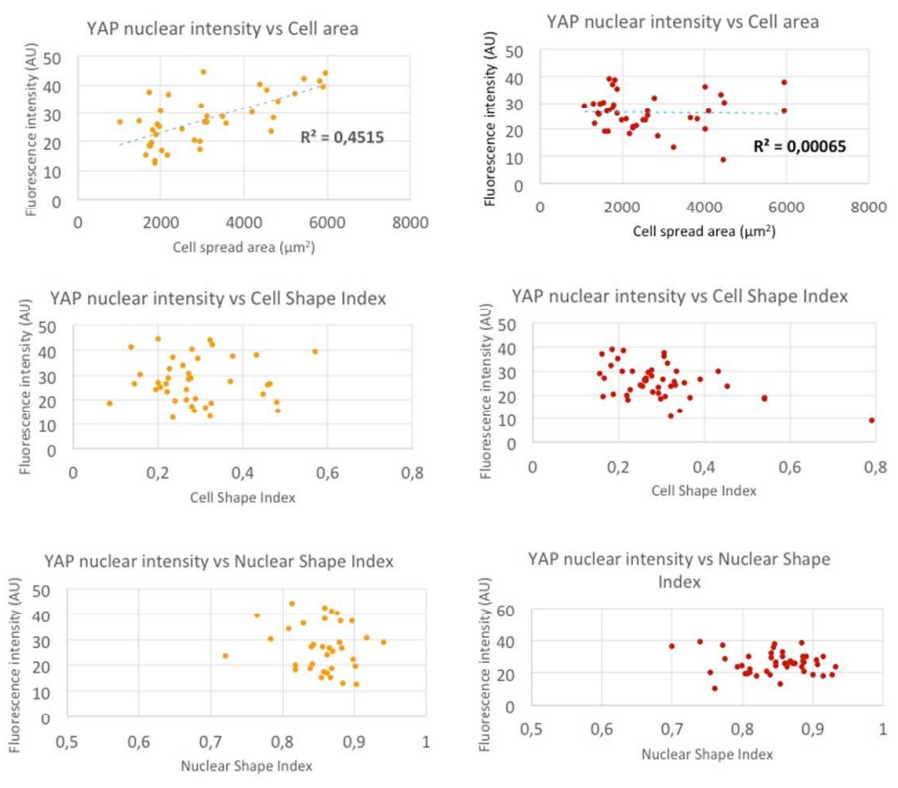

Figure S5.3 - Plots of YAP nuclear intensity vs Cell area, Cell Shape Index and Nuclear Shape index at Control, $2 \%$ strain or $8 \%$ strain conditions 